\title{
Block off: an examination of new control room configurations and reduced crew sizes examining engineered production blocking
}

\author{
Neville A. Stanton ${ }^{1}$ (1) - Aaron P. J. Roberts ${ }^{1}$
}

Received: 3 September 2018 / Accepted: 28 January 2019 / Published online: 14 February 2019

(c) The Author(s) 2019

\begin{abstract}
Previous research has shown a potential bottleneck of communication of information between the sonar controller (SOC) and operations officer (OPSO) in submarine sound and control rooms. This research aimed to see if this bottleneck could be removed by co-locating the sound and control room teams. Further, it also looked at the effects of reducing the crew numbers. Ten teams preformed the return to periscope depth tasks during high and low demand in a simulated submarine control room. Activities and communications of the teams were recorded and compared with data from a baseline condition of contemporary operations. The findings show that the co-location of the sound room and control room teams relieved the bottleneck of communications between the SOC and OPSO. Although communications increased, this was more balanced across team members and more relative to operational demand. This was coupled with more efficient task completion, resulting in greater number of tasks being completed by the command teams. Reduced crewing led to greater communications between the remaining members of the team together with task shedding in the higher demand condition. Future research should contrast these findings with objective measures of task performance to better understand potential performance benefits.
\end{abstract}

Keywords Submarine $\cdot$ Team work $\cdot$ Communications $\cdot$ Networks $\cdot$ Reduced crew

\section{Introduction}

The digital revolution has seen advancements in technology, computing processing capacity and sensor capabilities that is changing ways of working across many domains (Brynjolfsson and McAfee 2011). In the submarine domain, research has sought to develop new software algorithms and architectures to make the tracking of contacts by submarines more efficient and accurate (Shar and Li 2000; Wang et al. 2011; Lim 2012). In almost every domain, there is a drive to maximise productivity and reduce economic cost (Ireland and Schuh 2008; Brynjolfsson and Hitt 2000; Devaraj and Kohli 2003; Huddlestone and Harris 2017; Schutte 2017). This relies on the interaction of human operators and technology, with growing interdependence in pursuit of purposeful, goal-directed behaviours - the definition of a sociotechnical system (Walker et al. 2009). However, new technology is frequently installed without adequate consideration of how

Neville A. Stanton

n.stanton@soton.ac.uk

1 University of Southampton, Boldrewood Innovation Campus, Burgess Road, Southampton, UK to obtain maximal utility from an upgrade from a sociotechnical perspective (Hamburger et al. 2011; Mankins 2009). Adopting a sociotechnical systems approach appreciates the complexities involved with systems and how their design can be improved (Stanton 2014; Stanton and Roberts 2017; Roberts and Stanton 2018; Klein et al. 2003).

The continuing advancement of technology means that sociotechnical systems will further transform ways of working to increase capability (Roco and Bainbridge 2003; Showalter 2005). This is evident across many domains including aircrafts (Rudisill 2000; Bruce et al. 1998; Stanton et al. 2016), surface vessels (Lützhöft and Dekker 2002; Negahdaripour and Firoozfam 2006) and gas/electric/nuclear power plants (Santos et al. 2008; Stanton et al. 2010). The requirements for future submarine platforms will be guided by advancements in technology, operational capability and economic constraints. This will likely include new instruments (e.g. unmanned underwater vehicles-UUVs), improved sensor capacity (e.g. higher fidelity sonar arrays), advancements in control room design and maintenance/ reduction of staffing requirements (Hewish 2002). It is critical that such advancement includes evaluation of new technologies and ways of working from a sociotechnical systems 
perspective (Hamburger et al. 2011; Stanton and Roberts 2017; Stanton et al. 2017).

\section{Social loafing}

A critical challenge in team environments is creating conditions where knowledge can effectively be shared between individuals to generate knowledge at the level of the team to support higher order objectives (Fiore et al. 2018; Roberts and Stanton 2018). It is important to understand cognition in the minds of individual operators, but also to examine cognition between the minds of individuals, the processes affording macrocognition (Klein et al. 2006; Cooke et al. 2008). Such processes are often supported by technologies to facilitate interdependence between operators (Stanton et al. 2010; Zhang and Patel 2006). However, such technologies can also have a negative impact upon team processes. Social loafing for example, increases in technology-supported and location distributed teams, with the potential for overall productivity loss (Simms and Nichols 2014; Suleiman and Watson 2008; Stanton et al. 2003). Social loafing refers to instances where individuals working in a group exert less effort than when working alone (Simms and Nichols 2014). The factors promoting social loafing are debated, but include individual accountability, uniqueness of operator, group size, supervisory input, fatigue and task difficulty (Simms and Nichols 2014; Suleiman and Watson 2008; Alnuaimi et al. 2010).

In many domains the drive to reduce economic costs of sociotechnical systems have been achieved by reducing crew size (Walters et al. 2000; Stanton et al. 2016; Salotti et al. 2014). The economic savings associated with reduced crew sizes can be substantial (Allender 2000) and in certain situations have been demonstrated to improve efficiency (Watkins et al. 2009). However, a primary consideration is the impact a reduction in crew size has upon team performance and operational safety (Salotti et al. 2014). It is suggested that larger team sizes can be detrimental to global task performance as conditions for social loafing are increased, with not all team members contributing maximally to global team objectives (Alnuaimi et al. 2010). An investigation of crew size therefore is not necessarily concerned with a manning reduction, but whether command team capacity is being optimally utilised.

\section{Engineering change}

The configuration of submarine control rooms has not changed greatly across a century of operations (Stanton 2014). The original designs were constrained by engineering principles such as the use of hull penetrating periscopes, and particular hull compositions requiring the control room to be positioned in a small space at the top of the submarine (Binns 2008; Burcher and Rydill 1995). A large number of such restrictions have been removed by engineering advancements, such as the introduction of non-hull penetrating optronics masts (Pratt 1988; Duryea et al. 2008). Furthermore, the historical requirement for a separate sound room area to reduce ambient noise when processing aural data, is no longer a necessity with the development of noise cancelling technologies and waterfall displays (Arrabito et al. 2005). Technological advancements such as these pave the way for new thinking in terms of control room design.

A previous study by Stanton et al. (2017) examined submarine command teams contemporary ways of working during a return to periscope depth (RTPD). It was found that command teams typically increase communications during situations of high demand, demonstrate a reliance on certain operators within the command team as information brokers and promote a dearth of direct communication between operators highly dependent on each other for task-relevant information. Pertinent examples of this included a bottleneck of information transition observed between the sonar controller (SOC) and the operations officer (OPSO), who provide the only direct link between the sound and picture rooms (Stanton 2014; Stanton and Roberts 2017; Roberts and Stanton 2018). Also, the target motion analysis operators (TMA)s rely on information from the sonar operators (SOP) $\mathrm{s}$ to integrate with visual data when generating contact solutions (Loft et al. 2015a, b). Yet the communication between these operators was amongst the lowest in the control room during a RTPD (Stanton et al. 2017).

A critical question concerns whether the design of the sociotechnical system itself causes a reduction in productivity, in the form of unintentionally engineered production blocking and/or social loafing (Stanton et al. 2003). The configuration of a team and the way in which technology supports communication can greatly influence the effectiveness of overall team performance (Stanton et al. 2015a), particularly as the number of communications that can occur between operators is finite (Roberts and Cole 2018). It is therefore important to consider if the configuration of contemporary control room designs optimises the relationship between operators and technology. Communication is critical for the attainment of team awareness, as such processes can be the determining factor in terms of team workload rather than the work itself (Stanton 2011; Salas et al. 2001; Carletta et al. 2000).

In the current work, two studies examined the impact a novel control room configuration had upon submarine command team performance; with two different crew sizes during high and low -demand RTPD scenarios. This builds on a previous study that examined current ways of working during RTPD scenarios, which was used as a baseline comparator (Stanton et al. 2017). 


\section{Method}

The current study builds upon previous work examining the performance of submarine command teams in a control room configuration based upon the currently operational Astute class submarine (baseline). An in-depth investigation of the baseline studies has been completed (Stanton et al. 2017). The aim of the current study is firstly to evaluate the co-location configuration and reduced crew size condition in isolation and secondly to compare these results directly to the baseline configuration.

\section{Participants}

A total of 150 participants, 130 males and 20 females with an age range of 18-55 (mean 27.89, SD 7.86), were recruited opportunistically using posters and by directly contacting organisations with a military interest; participation was voluntary. Use of novice teams was justified by the fact that relative, rather than absolute, differences between conditions (and direction of those effects) were of most interest (Walker et al. 2010a, b). Participants were randomly allocated to one condition based on time of recruitment (baseline studies were run first). Ten teams of eight individuals, 71 males and 9 females with an age range of 18-55 (mean 26.83, SD 8.69), were recruited for the baseline study. In the co-location configuration (study one) 59 males and 11 females participated (in ten teams of seven) with an age range of 20-48 (mean 28.94, SD 7.02). The same (as study one) cohort of participants were used in the reduced crew size condition (study two) but two operators were removed from the team, with a total of 44 males and six females (ten teams of five) remaining with an age range of 20-48 (mean
28.98, SD 7.28). One team in baseline and one team for both study one and two were submariners from the British Royal navy (RN). Ethical approval was received from the University of Southampton Research Ethics Committee (Protocol No: 10099) and MoDREC (Protocol No: 551/MODREC/14).

\section{Equipment: the submarine control room simulator}

A submarine control room simulator was built to be representative of a currently operational RN submarine (for fuller description see Roberts et al. 2015, see Fig. 1a for configuration). The control room had nine networked workstations which had the simulation engine dangerous waters (DW) installed. This featured networked workstations for each of the operator roles included in the simulator. The roles chosen for inclusion in the control room were informed by subject matter experts (SME) and included an officer of the watch station (OOW), an operations officer station (OPSO), a sonar controller station (SOC), two target motion analysis stations (TMA), two sonar operator stations (SOP), a ship control station (SHC) and a periscope station (PERI). In all studies the role of the OOW was assumed by an experimenter in order to guide the scenarios tactically. In study one, the configuration of the control room was changed (see Fig. 1b) based upon the findings of baseline studies and input from human factors and SMEs and submarine operation SMEs. The only change made was to the configuration of the control room, all other aspects remained the same to avoid experimental confounds.

Two RTPD scenarios were designed with SME input and programmed in DW (see Table 1). Each scenario lasted approximately $45 \mathrm{~min}$ and the movements of contacts were predetermined to be consistent across all teams. The simulator was equipped with suite of recording devices such as web

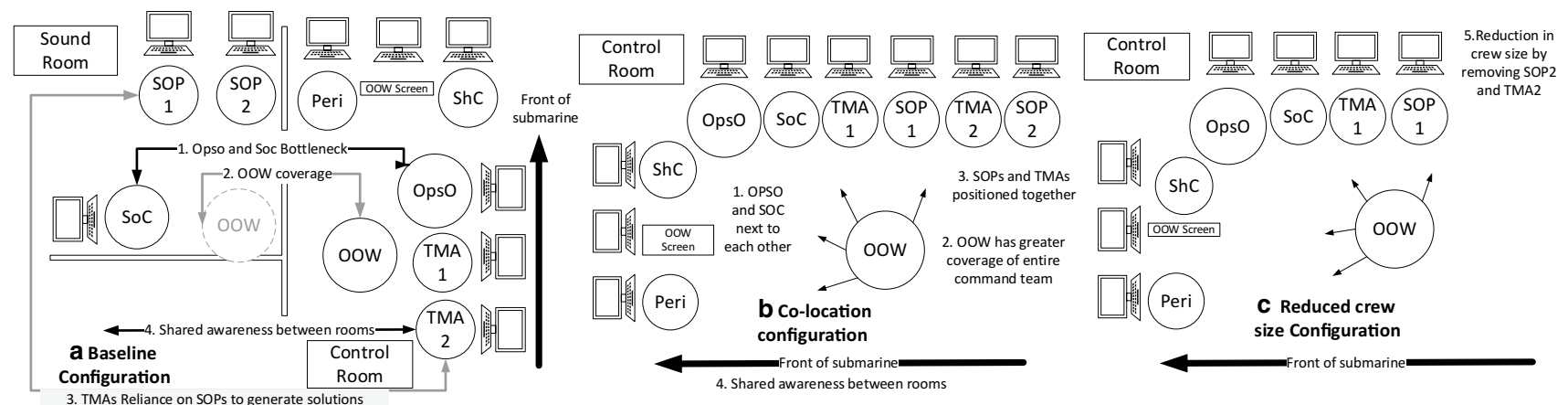

Fig. 1 Control room configurations. a Is the baseline configuration. The critical issues that required addressing based upon SME recommendations included: (1) the bottleneck in communications between OPSO and SOC, (2) OOW being required to supervise two separate rooms, (3) TMAs and SOPs being highly reliant on each other for task-relevant information but being distant (in terms of network composition and physical location) and (4) a requirement for shared awareness between the sound room and control room. b Is the novel configuration proposed by the SME panel to be investigated. $\mathbf{c}$ Is the co-location configuration with a reduced crew size (SOP1 and TMA1 removed) 
Table 1 Description of scenarios designed

\begin{tabular}{llll}
\hline Name & Demand & No. contacts & Mission \\
\hline Return to periscope depth (RTPD) & Low & 4-fishing & $\begin{array}{c}\text { RTPD from deep to send intelligence home, large temporal window of } \\
\text { opportunity. All contacts held must be ranged to find optimum course for } \\
\text { RTPD. Scenario complete once periscope has marked all contacts }\end{array}$ \\
& High & $\begin{array}{c}\text { 9-fishing } \\
\text { 3-catamaran } \\
\text { 1-biological }\end{array}$ & $\begin{array}{c}\text { RTPD as quickly as possible due to submarine damage. Attempt to range all } \\
\text { contacts to find optimum RTPD course }\end{array}$ \\
& & & \\
\hline
\end{tabular}

cameras and ambient microphone which allowed the recording of all communications that occurred between operatives.

\section{Design}

The co-location configuration was examined independently using a $2 \times 9$ mixed design (social networks), a $2 \times 14$ repeated measures design (information networks) and a $2 \times 12$ repeated measures design (task networks). The design of study two was identical to study one, except a $2 \times 7$ mixed design was employed for the social networks when investigating the reduced crew size in isolation. The independent variables were scenario demand (within subjects), operator role (between subjects-social network), information type (within subjects-information network) and task type (within subjects - task network). Scenario demand was manipulated by the number of contacts detectable in the scenario, contact behaviour (e.g. speed and course changes vs. steady) and area of operation (see Table 1). The design of scenarios was informed by SMEs to be representative of real high and low-demand RTPD operations. The dependent variables were static adjacency matrices (social, information and task) derived from the communications that took place between operators within the command team.

The co-location configuration and reduced crew size condition were then compared to baseline, extended the study design employing a $2 \times 2 \times 9$ mixed design (social networks), a $2 \times 2 \times 14$ mixed design (information networks) and a $2 \times 2 \times 12$ repeated measures design (task networks). For the reduced crew size configuration a $2 \times 2 \times 7$ mixed design was used to compare the reduced crew to baseline. The comparison of the configurations was between subjects.

\section{Procedure}

The procedure used was identical for all conditions, and the training and testing protocol remained the same. Participants attended the submarine simulator for two full days in baseline studies, and three full days for the co-location and reduced crew size studies ( $8 \mathrm{am}-5 \mathrm{pm})$. Informed consent was obtained on the first day prior to a simulation induction and random assignment of team roles. On the first day (training) the morning was spent watching a set of general submarine control room operation tutorials, and in the afternoon participants watched workstation specific tutorials and practiced tasks both individually and as a functional command team. Regular breaks and refreshments were provided between tutorials, with each tutorial lasting approximately $45 \mathrm{~min}$.

Participants started the second day (testing) with a refresher training scenario as a functional command team. During the refresher scenario, performance was assessed by experimenters to check that all tasks were being completed accurately in line with set criteria provided by SMEs (e.g. adequately detecting surrounding vessels and gaining solutions concerning surrounding vessels). After this the first scenario was begun - all recording devices were started and a verbal time stamp was read aloud for synchronisation purposes. At the start of each scenario the OOW gave a briefing outlining the mission objectives (see Table 1). When this mission objective had been achieved the end of the scenario was called and participants were given a short break before the start of the next scenario. Scenario presentation was counterbalanced across the 20 teams in order to reduce order effects. Each team completed both scenarios and participants occupied the same positions in the command team for both. At the end of the final scenario participants were provided with a full debrief and thanked for participating. Participants in the co-location configuration and reduced crew size condition attended for a third day, which followed the same procedure, without the refresher training scenario. To prevent practice effects the order of participation (study one vs. study two) was also counterbalanced.

\section{Analysis of data}

A new shortened version of Event Analysis for Systemic Teamwork (EAST: Stanton et al. 2008) was used to analyse the data. EAST examines complex sociotechnical systems using a network approach. This method has been presented in a previous study to model submarine command and control (Stanton 2014) and was used in the baseline study (Stanton et al. 2017). The framework has also been applied in other domains such as emergency services 
(Houghton et al. 2006), road safety (Salmon et al. 2014), air traffic control (Walker et al. 2010a) aviation (Stewart et al. 2008) and military risk assessment (Stanton and Harvey 2017). EAST facilitates an understanding of the processes undertaken by a submarine command team having completed an RTPD, utilising a network approach to understand how people, technology, information and tasks were connected. Firstly, social networks analyse communications taking place between 'agents' in the system. Secondly, the information networks describe information nodes or 'elements' that different agents in the system use and communicate during task performance. Finally, task networks describe the relationships between tasks, their sequence and interdependences.

The social, information and task networked were generated from the raw data from video and microphone recordings. The top 14 information elements (according to frequency count) were included in the statistical analysis of the information nodes. The information nodes were determined using Leximancer software (version 2.1), a software program for identifying concepts in text documents. Networks were processed using AGNA software (version 2.1.1-a software program for computing social network metrics). AGNA was also used to compute whole network metrics and nodal metrics (for definitions see Table 2).

The analysis of data was completed in two stages. Firstly, each experimental condition was examined independently. For the co-location configuration, the effect of scenario demand on global network metrics (for social and information networks) was examined using dependent $t$ tests. A $2 \times 9$ (demand $\times$ operators) mixed analyses of variances (ANOVAs) were conducted to examine the effect of scenario demand and operator role. The effect of scenario demand on information node metrics was examined using $2 \times 14$ (demand $\times$ information nodes) repeated measures ANOVAs. $2 \times 12$ (demand $\times$ task nodes) repeated measures ANOVAs were conducted to examine differences in the frequency of task completion between scenarios of high and low demand. The statistical analysis for the reduced crew size (study 2 ) was almost identical, except a $2 \times 7$ (demand $\times$ operators) mixed ANOVAs was used to examine individual nodes when looking at the reduced crew size independently. In the interests of completeness, the statistical analysis of the baseline tests were reported in the tables, however the results were not discussed in more detail as they are reported in the baseline studies and are outside of the scope of the current work. All other significant main effects were examined by conducting post hoc pairwise comparisons. To account for multiple comparisons the Bonferroni correction method was used ( $\alpha=0.05 /$ number of comparisons).

Secondly, a comparison of the co-location to the baseline configuration was examined. $2 \times 2$ mixed ANOVAs were conducted to examine the effect of configuration and scenario demand on global network metrics (for social and information networks). The effect of configuration, scenario demand and operator role on social node metrics was examined using $2 \times 2 \times 9$ (manipulation $\times$ demand $\times$ operators) mixed ANOVAs. To examine the effect of configuration and scenario demand on information node metrics $2 \times 2 \times 14$ (manipulation $\times$ demand $\times$ information nodes) mixed ANOVAs were conducted. Differences in the frequency of task completion based upon configuration and demand were examined using $2 \times 2 \times 12$ (manipulation $\times$ demand $\times$ task nodes) repeated measures ANOVAs. The statistical analysis for the reduced crew size comparison to baseline was almost identical, except a $2 \times 2 \times 7$ mixed ANOVAs were conducted to examine individual social nodes in the social network between baseline and the reduced crew size. When reporting the results of the configurations comparison main effects of demand were not reported, instead the interactions between demand and manipulation was focused upon, as this was the primary interest of the current work. All statistical analysis was conducted using IBM SPSS v21.

\section{Results for co-location configuration}

\subsection{Social network analysis}

In the co-location configuration the average frequency of communications between operators in the command team
Table 2 Definitions of global network metrics and node metrics

\begin{tabular}{ll}
\hline Metric & Definition \\
\hline Nodes & Entities in a network (people, information or tasks for the purposes of this paper) \\
Edges & Pairs of connected entities \\
Density & Number of relations observed represented as a fraction of the total relations possible \\
Cohesion & Number of reciprocal connections in the network divided by number of possible connections \\
Emission & Number of links emanating from node in the network \\
Reception & Number of links emanating going to each node in the network \\
Sociometric & Number of emissions and receptions relative to the number of nodes in the network \\
Centrality & Extent to which network revolves around a single node \\
\hline
\end{tabular}


varied depending on command team role and scenario demand (see Fig. 2-key nodes highlighted in black). The overall composition of both networks is similar, however the volume of interactions between operators increased during the high demand co-location RTPD scenarios.

\subsection{Whole network metrics}

The number of edges $\left(t_{9}=-3.42, p<0.05, r=0.75\right)$, density $\left(t_{9}=-3.62, p<0.05, r=0.77\right)$ and total interactions $\left(t_{9}=-9.15, p<0.05, r=0.95\right)$ statistically significantly increased in the high demand co-location condition when compared to low demand. The total number of edges $\left(F_{1,18}=5.57, p<0.05, \dot{\eta}_{\mathrm{p}}^{2}=0.24\right)$, density $\left(F_{1,18}=4.98\right.$, $\left.p<0.05, \hat{\eta}_{\mathrm{p}}^{2}=0.22\right)$, and cohesion $\left(F_{1,18}=33.24, p<0.01\right.$, $\left.\dot{\eta}_{\mathrm{p}}^{2}=0.65\right)$ of the entire networks were statistically significantly affected by configuration type. This indicates that the structure of the social networks fundamentally changed as a result of the new configuration (see Fig. 2; Table 3).

\section{Nodal metrics}

\subsection{Emissions}

In the co-location configuration the total emissions of each node were statistically significantly affected by scenario demand $\left(F_{1,81}=303.64, p<0.01, \dot{\eta}_{\mathrm{p}}^{2}=0.79\right)$ and operator role $\left(F_{8,81}=66.23, p<0.01, \dot{\eta}_{\mathrm{p}}^{2}=0.87\right)$. The interaction of scenario demand and role also statistically significantly affected total node emissions $\left(F_{8,81}=18.24, p<0.01, \hat{\eta}_{\mathrm{p}}^{2}=0.64\right)$. When examining the effect of scenario demand, post hoc analysis revealed that overall, emissions were statistically significantly higher $(p<0.05)$ in the high demand RTPD condition than the low-demand condition. All operators except PERI and SHC had statistically $(p<0.05)$ higher emissions in the high demand condition than the lowdemand condition. When examining the effect of role post hoc analysis revealed that OPSO had statistically significantly higher $(p<0.05)$ emissions than all other operators (see Table 4; Fig. 2). OOW and SOC had statistically significantly $(p<0.05)$ more emissions than all operators except
Fig. 2 Social network diagrams for low and high demand co-location RTPD scenarios. OPSO had the largest volume of emissions and receptions of all operators. Overall, communications between operators were more evenly distributed when compared to baseline. In particular the bottleneck between OPSO and SOC (highlighted in black) had been reduced and communications between the SOPS and TMAs (highlighted in grey) were greatly increased

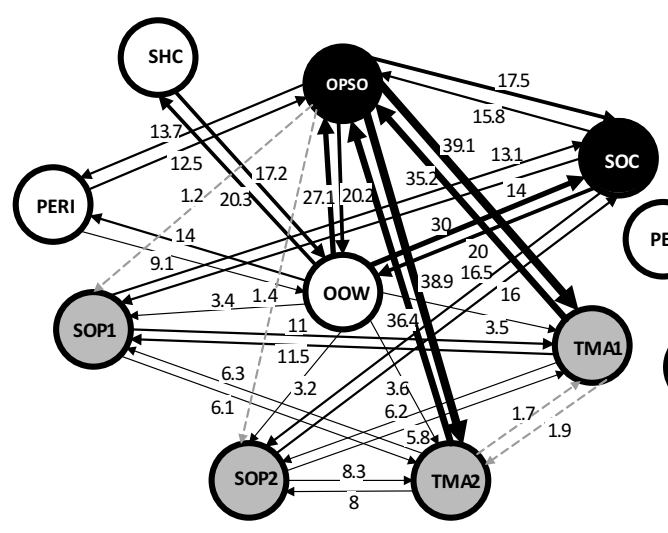

a RTPDL Co-location configuration

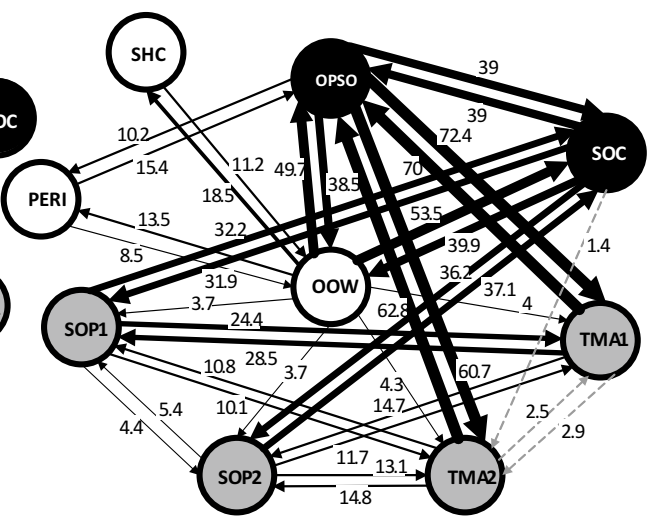

b RTPDH Co-location configuration

Table 3 Social network metrics for whole network RTPD baseline and co-location configuration

\begin{tabular}{|c|c|c|c|c|c|c|}
\hline & \multicolumn{4}{|l|}{ RTPD } & \multirow{3}{*}{$\begin{array}{l}\text { Effect of demand co- } \\
\text { location configuration }\end{array}$} & \multirow{3}{*}{$\begin{array}{l}\text { Effect of } \\
\text { configura- } \\
\text { tion }\end{array}$} \\
\hline & \multicolumn{2}{|c|}{ Baseline configuration } & \multicolumn{2}{|c|}{ Co-location configuration } & & \\
\hline & Low & High & Low & High & & \\
\hline Edges & $36.80 \pm 3.01$ & $36.50 \pm 4.93$ & $32.90 \pm 1.97$ & $35.60 \pm 2.07$ & $3.42 *$ & $5.57 *$ \\
\hline Density & $0.51 \pm 0.04$ & $0.51 \pm 0.07$ & $0.46 \pm 0.03$ & $0.50 \pm 0.03$ & $3.61 *$ & $4.98 *$ \\
\hline Cohesion & $0.34 \pm 0.03$ & $0.35 \pm 0.03$ & $0.40 \pm 0.04$ & $0.42 \pm 0.02$ & 1.72 & $33.23 * * *$ \\
\hline Total interactions & $663.80 \pm 206.32$ & $816.10 \pm 221.10$ & $511.70 \pm 72.88$ & $904.10 \pm 169.81$ & $9.15^{* * *}$ & 0.28 \\
\hline
\end{tabular}

$* p<0.05$

*** $p<0.001$ 


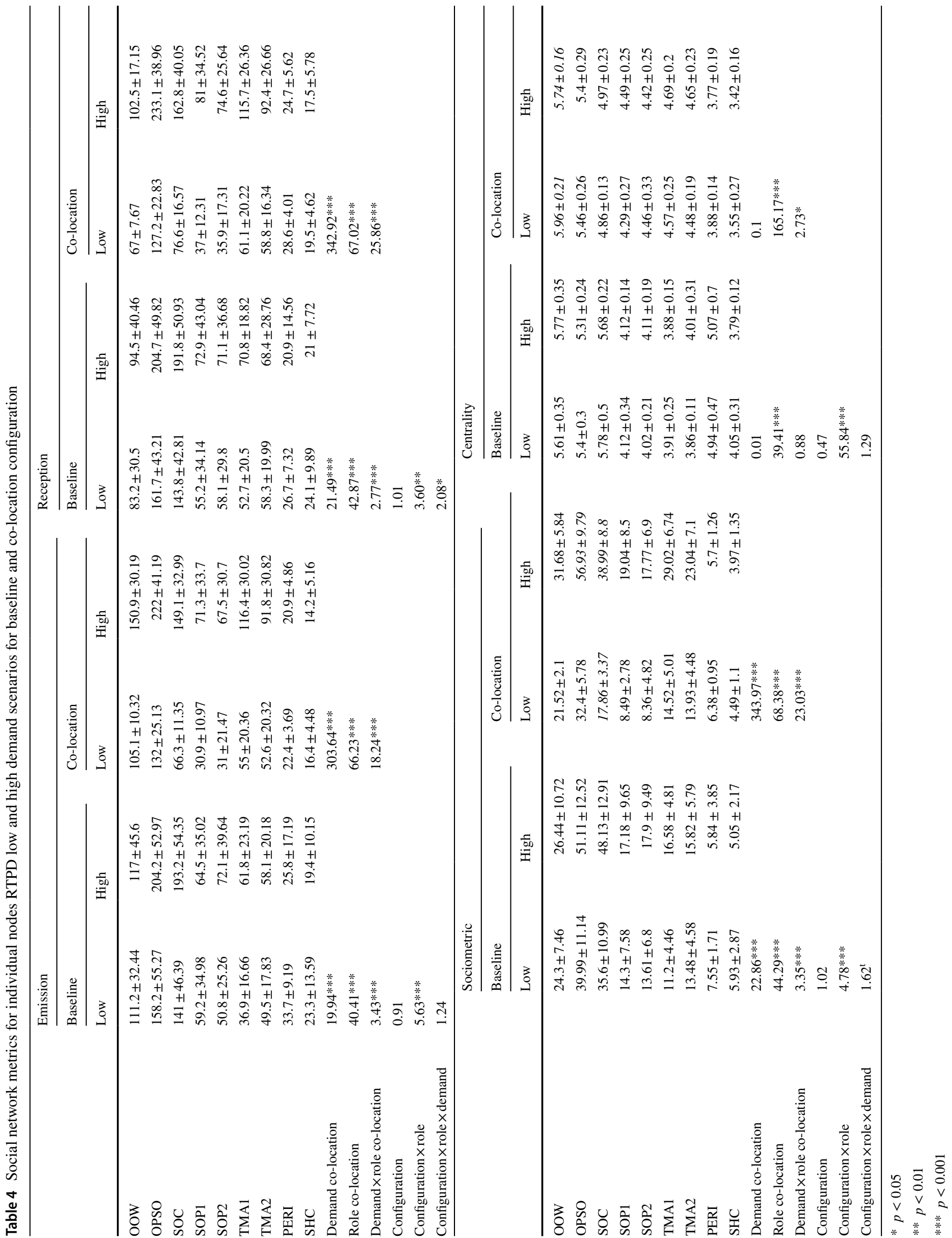


OPSO. PERI and SHC had statistically significantly $(p<0.05)$ less emissions than all operators. When examining the interaction between demand and role post hoc analysis revealed that OOW had statistically significantly $(p<0.05)$ more emissions than SOC in the low-demand condition but not in the high demand condition. SOP1 and SOP2 had statistically significantly $(p<0.05)$ higher emissions than SHC and PERI in the high demand condition but no significant differences were observed in the low-demand condition.

The total emissions of each node were not statistically significantly affected by configuration type $\left(F_{1,162}=0.91\right.$, $p>0.05)$. The interaction of configuration type and role statistically significantly affected total emissions $\left(F_{8,162}=5.63\right.$, $p<0.01, \hat{\eta}_{\mathrm{p}}^{2}=0.22$ ). The interaction of configuration type, role and demand did not statistically significantly affect emissions $\left(F_{8,162}=1.24, p>0.05\right)$. Post hoc analysis revealed SOC, SHC and PERI had statistically significantly $(p<0.05)$ less emissions in the co-location configuration than baseline. TMA1, TMA2 had statistically significantly $(p<0.05)$ more emissions in the co-location configuration compared to baseline.

\subsection{Receptions}

In the co-location configuration the total receptions of each node were significantly affected by scenario demand $\left(F_{1,81}=342.92, p<0.01, \dot{\eta}_{\mathrm{p}}^{2}=0.81\right)$ and operator role $\left(F_{8,81}=67.22, p<0.01, \dot{\eta}_{\mathrm{p}}^{2}=0.87\right)$. The interaction of scenario demand and role also statistically significantly affected total node receptions $\left(F_{8,81}=25.89, p<0.01, \dot{\eta}_{\mathrm{p}}^{2}=0.72\right)$. When examining the effect of scenario demand, post hoc analysis revealed overall, receptions were statistically significantly higher $(p<0.05)$ in the high demand RTPD condition than the low-demand condition. When examining the effect of role post hoc analysis revealed that OPSO had statistically significantly higher $(p<0.05)$ receptions than all other operators (see Table 4; Fig. 2). SOC had statistically significantly $(p<0.05)$ more receptions than all operators (except OPSO). All operators had statistically significantly $(p<0.05)$ more receptions than SHC and PERI. When examining the interaction of demand and role post hoc analysis revealed SOC had statistically significantly $(p<0.05)$ more receptions than OOW, TMA1 and TMA2 in the high demand condition but no significant difference between these operators was observed in the low-demand condition. OOW had statistically significantly more receptions than SOP1 and SOP2 in the low demand condition, but no significant difference was observed in the high demand condition. TMA1 and TMA2 had statistically significantly $(p<0.05)$ more receptions than SOP1 and SOP2 in the low-demand condition but no significant differences were observed in the high demand condition.
The total receptions of each node were not statistically significantly affected by configuration type $\left(F_{1,162}=1.01\right.$, $p>0.05)$. The interaction of configuration type and role statistically significantly affected total receptions $\left(F_{8,162}=3.60\right.$, $p<0.05, \hat{\eta}_{\mathrm{p}}^{2}=0.15$ ). The interaction of configuration type, role and demand statistically significantly affected receptions $\left(F_{8,162,}=2.08, p<0.05, \dot{\eta}_{\mathrm{p}}^{2}=0.15\right)$. Post hoc analysis revealed SOC had statistically significantly $(p<0.05)$ less receptions in the co-location configuration than baseline. TMA1 had statistically significantly $(p<0.05)$ more receptions in the co-location configuration compared to baseline. No significant differences in receptions between baseline and the colocation configuration were observed for OOW, OPSO, TMA2, SOP1, SOP2, SHC or PERI. Further analysis revealed that OPSO had statistically significantly $(p<0.05)$ fewer receptions in the co-location configuration lowdemand conditions than in baseline low demand configuration.

\subsection{Sociometric status}

In the co-location configuration the sociometric status of each node was significantly affected by scenario demand $\left(F_{1,81}=343.97, p<0.01, \dot{\eta}_{\mathrm{p}}^{2}=0.81\right)$ and operator role $\left(F_{8,81}=68.38, p<0.01, \dot{\eta}_{\mathrm{p}}^{2}=0.87\right)$. The interaction of scenario demand and role also statistically significantly affected sociometric status $\left(F_{8,81}=23.04, p<0.01, \dot{\eta}_{\mathrm{p}}^{2}=0.70\right)$. When examining the effect of scenario demand, post hoc analysis revealed overall, sociometric status was statistically significantly higher $(p<0.05)$ in the higher demand RTPD condition than the low-demand condition. All operators except PERI and SHC had statistically significantly higher sociometric status in the high demand condition than the lowdemand condition. When examining the effect of operator role post hoc analysis revealed OPSO had statistically significantly $(p<0.05)$ higher sociometric status than all other operators. OOW, SOC and TMA1 had statistically significantly $(p<0.05)$ higher sociometric status than all operators (except OPSO). When examining the interaction of demand and role post hoc analysis revealed TMA1 and TMA2 had statistically significantly $(p<0.05)$ higher sociometric status than SOP1 and SOP2 in the low demand condition but no significant difference was observed in the high demand condition.

The sociometric status of each node was not statistically significantly affected by configuration type $\left(F_{1,162}=1.02\right.$, $p>0.05$ ) or the interaction of configuration type, role and demand, although a non-significant trend was observed $\left(F_{8,162}=1.78, p=.99\right)$. The interaction of configuration type and role statistically significantly affected sociometric status $\left(F_{8,162}=4.78, p<0.01, \dot{\eta}_{\mathrm{p}}^{2}=0.19\right)$. Post hoc analysis revealed SOC and SHC had statistically significantly $(p<0.05)$ lower 
sociometric status in the co-location configuration than in the baseline condition. TMA1 and TMA2 had statistically significantly $(p<0.05)$ higher sociometric status in the colocation configuration compared to baseline. No significant differences in sociometric status between baseline and the co-location configuration were observed for OOW, OPSO, SOP1, SOP2 or PERI.

\subsection{Centrality}

The centrality of each node was not statistically significantly affected by scenario demand $\left(F_{1,81}=0.1, p>0.05\right)$ but was significantly affected by operator role $\left(F_{8,81}=165.17\right.$, $\left.p<0.01, \hat{\eta}_{\mathrm{p}}^{2}=0.94\right)$ and the interaction between scenario demand and role $\left(F_{8,81}=2.76, p<0.05, \hat{\eta}_{\mathrm{p}}^{2}=0.21\right)$. When examining the effect of role post hoc analysis revealed OOW had statistically significantly $(p<0.05)$ higher centrality than all operators. OPSO had statistically significantly higher centrality than all operators (except OOW). SOC had statistically significantly $(p<0.05)$ higher centrality than all operators (except OPSO and OOW).

The centrality of each node was not statistically significantly affected by configuration type $\left(F_{1,162}=0.47, p>0.05\right)$ or the interaction of configuration type, role and demand $\left(F_{8,162}=1.29, p>0.05\right)$. The interaction of configuration type and role statistically significantly affected sociometric status $\left(F_{8,162}=55.84, p<0.01, \dot{\eta}_{\mathrm{p}}^{2}=0.73\right)$. Post hoc analysis revealed SOC, PERI and SHC had statistically significantly $(p<0.05)$ lower centrality in the co-location configuration than in the baseline condition. TMA1, TMA2, SOP1 and SOP2 had statistically significantly $(p<0.05)$ higher centrality in the co-location configuration compared to baseline.

\subsection{Information network analysis}

In the co-location configuration the structure of the information networks is relatively consistent in both high and low-demand RTPD scenarios with 'contact', 'bearing' and 'course' the most connected information pieces (see Fig. 3). The volume of emissions from most information elements appeared to increase in the high-demand RTPD scenarios although differences in relationships can be observed (see Tables 5, 6).

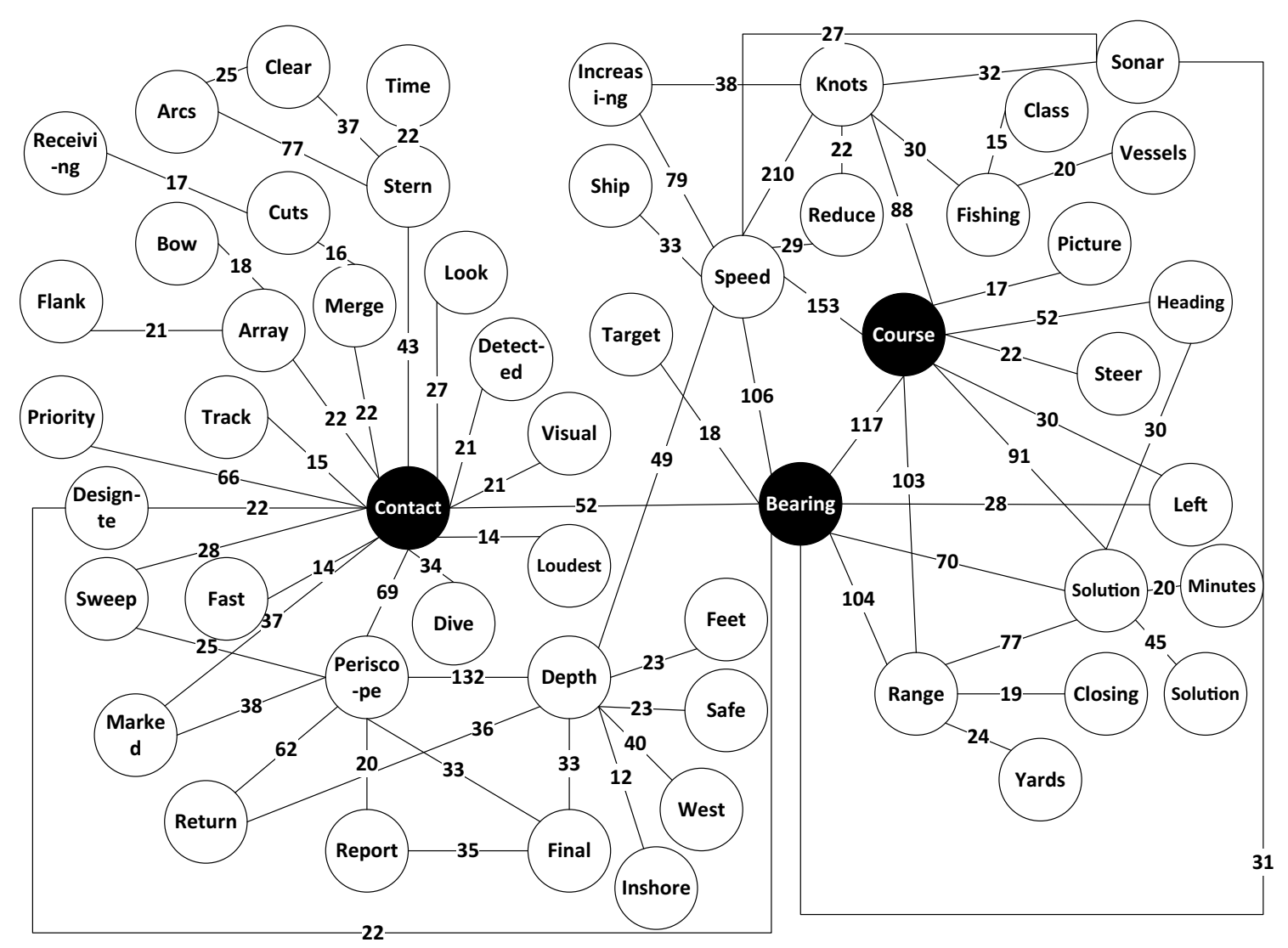

Fig. 3 Information network RTPD low-demand co-location configuration. The nodes with the highest centrality were similar to baseline, including contact, bearing and course (highlighted in black) 
Table 5 Information network metrics for entire network RTPD co-location and baseline

\begin{tabular}{|c|c|c|c|c|c|c|c|}
\hline & \multicolumn{2}{|l|}{ Baseline } & \multicolumn{2}{|l|}{ Co-location } & \multirow{2}{*}{$\begin{array}{l}\text { Demand co- } \\
\text { location }\end{array}$} & \multirow{2}{*}{$\begin{array}{l}\text { Effect of } \\
\text { configura- } \\
\text { tion }\end{array}$} & \multirow{2}{*}{$\begin{array}{l}\text { Demand } \times \text { con- } \\
\text { figuration }\end{array}$} \\
\hline & Low & High & Low & High & & & \\
\hline Nodes & $45.60 \pm 5.10$ & $44.40 \pm 6.46$ & $49.5 \pm 5.95$ & $55.1 \pm 3.81$ & $2.74 *$ & $17.31 * * *$ & 4.12 \\
\hline Edges & $702.10 \pm 330.28$ & $644.80 \pm 357.54$ & $655.6 \pm 130.36$ & $776.8 \pm 143.89$ & $3.27 *$ & 0.16 & 3.04 \\
\hline Density & $0.49 \pm 0.15$ & $0.49 \pm 0.19$ & $0.26 \pm 0.04$ & $0.26 \pm 0.04$ & 1.06 & $19.77 * * *$ & 0.16 \\
\hline Diameter & $3.30 \pm 0.82$ & $3.5 \pm 0.53$ & $3.7 \pm 0.67$ & $3.8 \pm 0.63$ & 0.43 & 1.83 & 0.11 \\
\hline $\begin{array}{l}\text { Total interac- } \\
\text { tion }\end{array}$ & $2412.10 \pm 1424.21$ & $2898.90 \pm 2620.68$ & $1864.00 \pm 614.28$ & $2597.40 \pm 730.31$ & $3.24 * * *$ & 0.46 & 0.16 \\
\hline
\end{tabular}

$* p<0.05$

$* * * \quad p<0.001$

\subsection{Whole network metrics}

In the co-location configuration statistically significantly more emissions $\left(t_{9}=3.24, p<0.05, d=1.20\right)$, nodes $\left(t_{9}=2.74, p<0.05, d=1.20\right)$ and edges $\left(t_{9}=3.27, p<0.05\right.$, $d=1.20)$ in the high-demand condition compared to low demand (see Table 5), indicating that the overall structure of information varied based upon scenario demand. Configuration statistically significantly affected the number of nodes $\left(F_{1,18}=17.31, p<0.01, \dot{\eta}_{\mathrm{p}}^{2}=0.49\right)$ and network density $\left(F_{1,18}=19.78, p<0.01, \hat{\eta}_{\mathrm{p}}^{2}=0.52\right)$. The overall network density was statistically significantly $(p<0.05)$ lower in the co-location configuration compared to baseline, but the number of nodes were statistically significantly $(p<0.05)$ higher in the co-location configuration compared to baseline.

\section{Nodal metrics}

\subsection{Emissions}

In the co-location configuration the total emissions of each node were statistically significantly affected by scenario demand $\left(F_{1,126}=40.36, p<0.01, \dot{\eta}_{\mathrm{p}}^{2}=0.24\right)$ and concept type $\left(F_{13,126}=15.98, p<0.01, \hat{\eta}_{\mathrm{p}}^{2}=0.62\right)$. A statistically significant $\left(F_{13,126}=2.54, p<0.01, \hat{\eta}_{\mathrm{p}}^{2}=0.21\right)$ interaction between demand and concept was also observed. Emissions were statistically significantly higher $(p<0.05)$ in the high-demand RTPD condition than the low-demand condition. Further analysis revealed bearing, contact, course, speed and solution had statistically significantly $(p<0.05)$ more emissions than all other information (see Fig. 3; Table 6). The total emissions of each node were statistically significantly affected by configuration type $F_{1,252}=15.59, p<0.05, \dot{\eta}_{\mathrm{p}}^{2}=0.15$. The total number of emissions was statistically significantly $(p<0.05)$ lower in the co-location configuration.

\subsection{Receptions}

In the co-location configuration the total receptions of each node were statistically significantly affected by scenario demand $\left(F_{1,126}=40.36, p<0.01, \dot{\eta}_{\mathrm{p}}^{2}=0.24\right)$ and concept type $\left(F_{13,126}=15.98, p<0.01, \hat{\eta}_{\mathrm{p}}^{2}=0.62\right)$. A statistically significant $\left(F_{13,126}=2.54, p<0.01, \dot{\eta}_{\mathrm{p}}^{2}=0.21\right)$ interaction between demand and concept was also observed. Receptions were statistically significantly higher $(p<0.05)$ in the high demand RTPD condition than the low demand condition. Further analysis revealed bearing, contact, course, speed and solution had statistically significantly $(p<0.05)$ more receptions than all other information. The total receptions of each node were statistically significantly affected by configuration type $F_{1,252}=15.59$, $p<0.05, \hat{\eta}_{\mathrm{p}}^{2}=0.15$. The total number of receptions was statistically significantly $(p<0.05)$ lower in the co-location configuration.

\subsection{Sociometric status}

In the co-location configuration the sociometric status of each node was statistically significantly affected by scenario demand $\left(F_{1,126}=16.41, p<0.01, \hat{\eta}_{\mathrm{p}}^{2}=0.28\right)$ and concept type $\left(F_{13,126}=17.50, p<0.01, \hat{\eta}_{\mathrm{p}}^{2}=0.64\right)$. A statistically significant $\left(F_{13,126}=1.92, p<0.05, \eta_{\mathrm{p}}^{2}=0.17\right)$ interaction between demand and concept was also observed. Sociometric status was statistically significantly $(p<0.05)$ higher in the high demand condition. Further analysis revealed bearing, contact, course, speed, periscope, depth range and solution had statistically significantly $(p<0.05)$ higher sociometric status than all other information. The sociometric status of each node was 


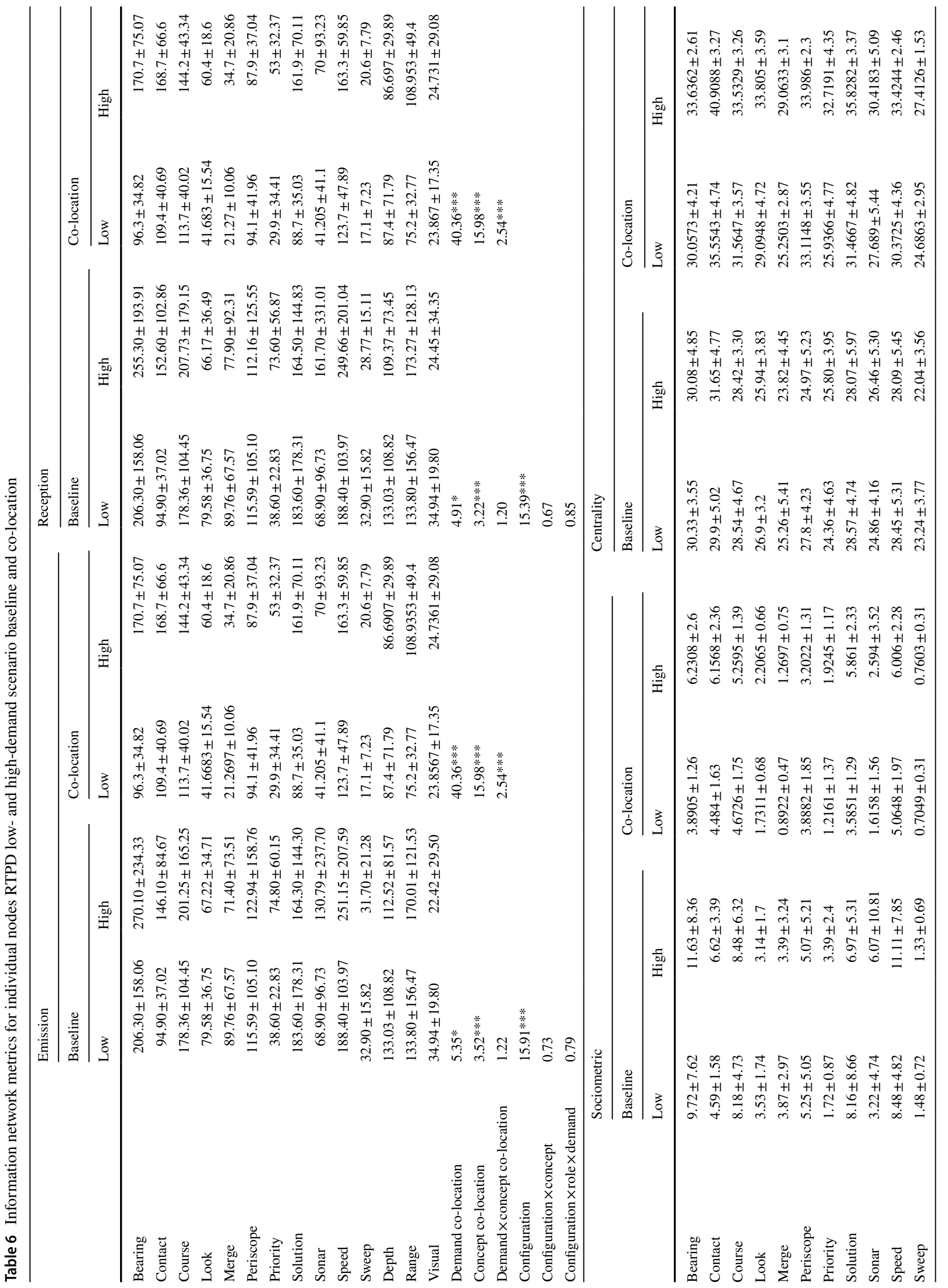




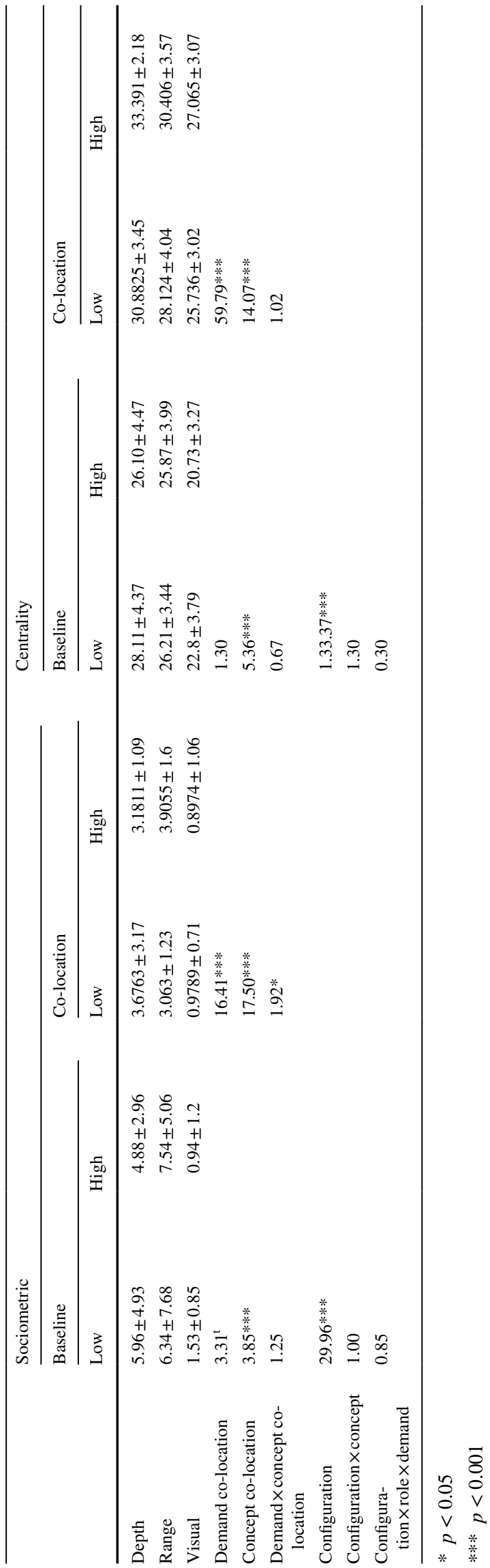


statistically significantly affected by configuration type $\left(F_{1,252}=29.96, p<0.01, \hat{\eta}_{\mathrm{p}}^{2}=0.11\right)$. Sociometric status was statistically significantly $(p<0.05)$ lower in the co-location configuration.

\subsection{Centrality}

In the co-location configuration the centrality of each node was statistically significantly affected by scenario demand $\left(F_{1,126}=59.79, p<0.01, \dot{\eta}_{\mathrm{p}}^{2}=0.60\right)$ and concept type $\left(F_{13,126}=5.36, p<0.01, \dot{\eta}_{\mathrm{p}}^{2}=0.36\right)$. Centrality was statistically significantly $(p<0.05)$ higher in the high demand condition. Further analysis revealed that contact had statistically significantly $(p<0.05)$ higher centrality than all other information. The centrality of each node was statistically significantly affected by configuration type $\left(F_{1,252}=133.37, p<0.01, \dot{\eta}_{\mathrm{p}}^{2}=0.35\right)$. Centrality was statistically significantly $(p<0.05)$ lower in the co-location configuration.

\subsection{Task network analysis}

The type of tasks completed by the command team was the same during baseline and the co-location configuration (for both high and low-demand scenarios) as the fundamental task completed by operators did not change (see Fig. 4). The task with the highest number of emissions was 'building the sonar picture' which required the completion of numerous subtasks (i.e. data analysis and assimilation) to inform the generation of a tactical picture when operating at depth (see Table 7).

\subsection{Task frequency analysis}

In the co-location configuration the frequency of task completion was statistically significantly affected by scenario demand $\left(F_{1,189}=131.26, p<0.01, \dot{\eta}_{\mathrm{p}}^{2}=0.41\right)$ and task type $\left(F_{20,189}=32.01, p<0.01, \hat{\eta}_{\mathrm{p}}^{2}=0.77\right)$. A statistically significant interaction $\left(F_{20,189}=20.35, p<0.01, \hat{\eta}_{\mathrm{p}}^{2}=0.68\right)$ between scenario demand and task type was also observed. Post hoc analysis revealed the frequency of tasks completion was statistically significantly higher $(p<0.05)$ in the high-demand condition than the low-demand condition. The tasks detecting, designating, classifying, generating speed estimates and solutions from sonar were completed statistically significantly $(p<0.05)$ more frequently in the high demand condition. Further analysis revealed the tasks of detecting, classifying, generating speed estimates, and generating solution estimates from sonar were completed statistically significantly $(p<0.05)$ higher than all other tasks (see Table 7). All periscope related tasks (except detect and designate visual contacts) were completed statistically significantly $(p<0.05)$ less than all other tasks (except clear stern arcs and final reports).

The frequency of task completion was statistically significantly affected by configuration $\left(F_{1,378}=13.11, p<0.01\right.$, $\left.\eta_{\mathrm{p}}^{2}=0.43\right)$, the interaction of configuration and task type $\left(F_{20,378}=2.02, p<0.01, \hat{\eta}_{\mathrm{p}}^{2}=0.10\right)$ and the interaction of configuration, task type and demand $\left(F_{20,378}=2.54, p<0.01\right.$, $\left.\hat{\eta}_{\mathrm{p}}^{2}=0.12\right)$. Further analysis revealed statistically significantly $(p<0.05)$ more tasks were completed in the co-location configuration than the baseline configuration. The tasks of detecting visual and designating visual were completed statistically significantly $(p<0.05)$ more frequently in the colocation configuration than in baseline (in both the low and high demand conditions). The tasks of detecting and designating sonar contacts were completed statistically significantly $(p<0.05)$ more frequently in the high-demand colocation configuration than in the high-demand baseline configuration.

\section{Discussion for the co-location configuration}

In the co-location configuration, the effect of demand was similar to what was observed during baseline, with significantly more communications between operators being observed (Stanton et al. 2017). However, communications were distributed more evenly across the command team with a greater number of edges observed (i.e. more operators directly communicating) and greater cohesion. The facilitation of communication between more operators has the potential to facilitate knowledge generation at the level of the team (Fiore et al. 2010; Klein et al. 2006; Cooke et al. 2008). However, it is important that any increase in verbal communications is necessary and are not occurring simply due to the fact that the co-location configuration has facilitated them, or in fact required them due to information transition being made more difficult (Salas et al. 2001; Stanton 2011; Carletta et al. 2000). This does not seem to be the case as the difference between the high- and low-demand scenarios in the co-location configuration was much greater than in baseline (Stanton et al. 2017). It appears that the co-location configuration has enabled greater volumes of communication, which was utilised in the high demand scenarios. At the same time however, it also appears to have facilitated greater efficiency, with much lower verbal communications observed in the low-demand scenarios. The additional capacity was only utilised when required operationally. The bottleneck that was observed in baseline between OPSO and SOC was reduced, with communication between these 


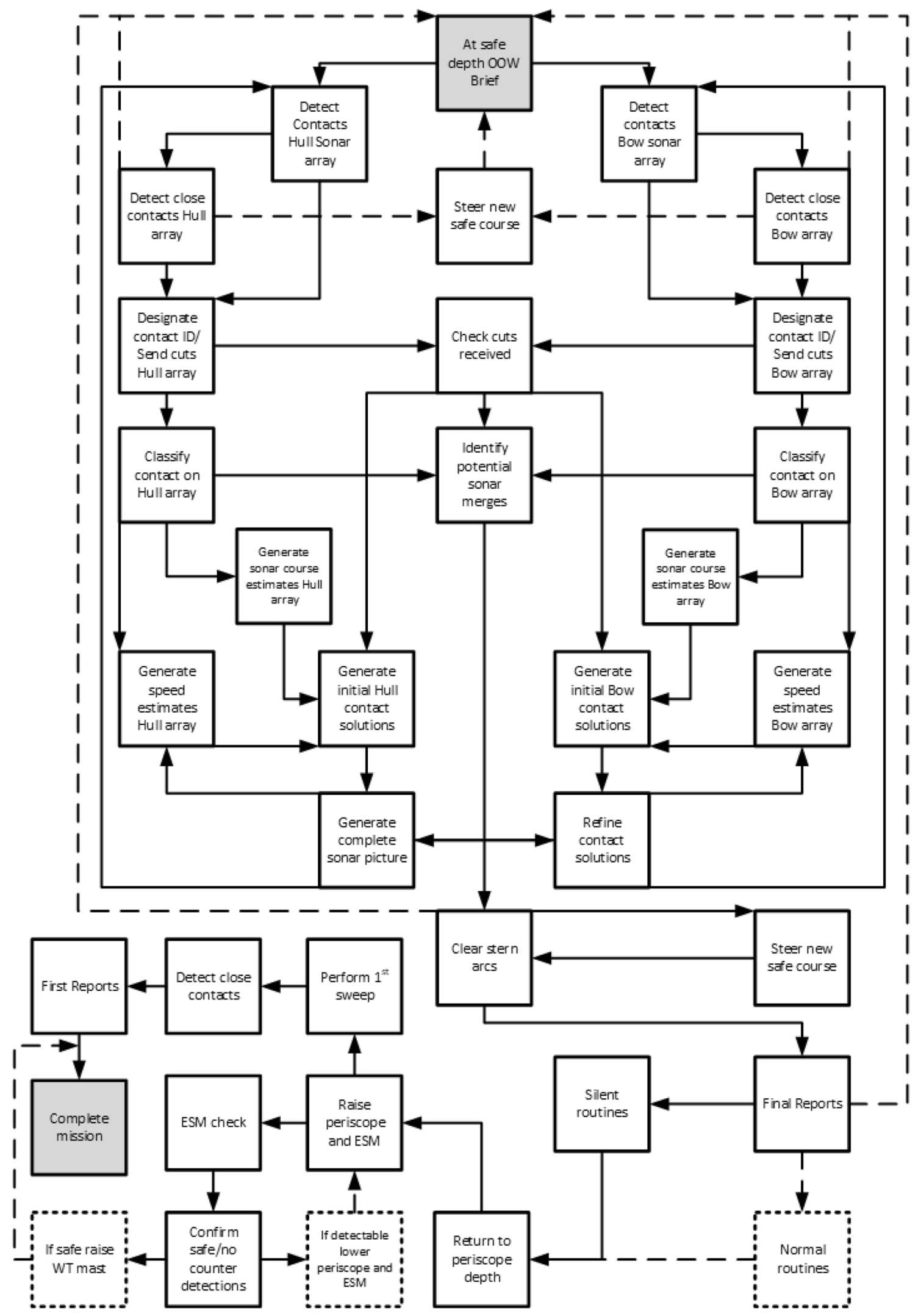

Fig. 4 Task network diagram for RTPD low- and high-demand scenarios 
Table 7 Task network metrics for individual nodes RTPD scenarios high- and low-demand scenarios (baseline and co-location configuration)

\begin{tabular}{|c|c|c|c|c|c|c|c|c|c|}
\hline & \multicolumn{5}{|c|}{ Node metrics } & \multicolumn{4}{|c|}{ Frequency of task completion } \\
\hline & $\begin{array}{l}\text { Emis- } \\
\text { sion }\end{array}$ & \multicolumn{2}{|c|}{ Reception } & $\begin{array}{l}\text { Sociomet- } \\
\text { ric }\end{array}$ & \multirow{2}{*}{$\begin{array}{l}\begin{array}{l}\text { Cen- } \\
\text { trality }\end{array} \\
12.59\end{array}$} & \multirow{2}{*}{$\begin{array}{l}\begin{array}{l}\text { Baseline } \\
\text { low }\end{array} \\
4 \pm 1.89\end{array}$} & \multirow{2}{*}{$\begin{array}{l}\begin{array}{l}\text { Baseline } \\
\text { high }\end{array} \\
8.7 \pm 4.22\end{array}$} & \multirow{2}{*}{$\begin{array}{c}\text { Co-location low } \\
3.1 \pm 1.66\end{array}$} & \multirow{2}{*}{$\begin{array}{c}\text { Co-location high } \\
12.4 \pm 2.91\end{array}$} \\
\hline Detect contacts sonar & 3 & 2 & & 0.19 & & & & & \\
\hline Designate sonar contact & 2 & 2 & & 0.15 & 11.35 & $3.3 \pm 1.64$ & $7.7 \pm 4.85$ & $2.5 \pm 1.27$ & $10.7 \pm 3.89$ \\
\hline Classify Sonar Contacts & 3 & 1 & & 0.15 & 11.72 & $3.8 \pm 1.87$ & $10.5 \pm 4.3$ & $2.6 \pm 1.78$ & $9.4 \pm 3.6$ \\
\hline Speed estimates & 1 & 3 & & 0.15 & 11.07 & $5.4 \pm 2.27$ & $10.9 \pm 5.67$ & $4.2 \pm 2.2$ & $10.9 \pm 3.84$ \\
\hline Sonar courses & 1 & 1 & & 0.08 & 10.29 & $1.2 \pm 1.23$ & $4.9 \pm 2.13$ & $4.9 \pm 1.45$ & $5.1 \pm 3.21$ \\
\hline Check cuts are received & 2 & 1 & & 0.12 & 11.35 & $2.4 \pm 1.84$ & $3.9 \pm 1.52$ & $3.5 \pm 2.07$ & $6.6 \pm 4.17$ \\
\hline Identify SONAR merges & 2 & 2 & & 0.15 & 12.24 & $3.4 \pm 1.35$ & $2.8 \pm 1.81$ & $3.3 \pm 1.34$ & $6.8 \pm 2.74$ \\
\hline Generate Solutions & 1 & 3 & & 0.15 & 12.66 & $4.6 \pm 1.96$ & $10.7 \pm 3.53$ & $4 \pm 0$ & $12.2 \pm 2.86$ \\
\hline Refine solutions & 3 & 3 & & 0.23 & 14.14 & $4.2 \pm 3.58$ & $5.1 \pm 3.63$ & $4.7 \pm 3.27$ & $5 \pm 3.2$ \\
\hline Submarine parameters & 2 & 2 & & 0.15 & 13.04 & $4.4 \pm 2.46$ & $4.3 \pm 2.06$ & $4.8 \pm 1.32$ & $4 \pm 1.33$ \\
\hline Raise Periscope & 2 & 2 & & 0.15 & 18.11 & $1 \pm 0$ & $0.8 \pm 0.42$ & $1 \pm 0$ & $1 \pm 0$ \\
\hline Complete Sweep & 1 & 1 & & 0.08 & 16.85 & $1.8 \pm 0.63$ & $0.8 \pm 0.42$ & $1.7 \pm 0.48$ & $1.1 \pm 0.32$ \\
\hline \multirow[t]{3}{*}{ Detect Visual contacts } & 1 & 1 & & 0.08 & 14.61 & $1.7 \pm 0.95$ & $1.4 \pm 1.07$ & $3.7 \pm 0.67$ & $3.9 \pm 1.85$ \\
\hline & \multicolumn{5}{|c|}{ Total tasks completed } & $48.20 \pm 9.07$ & $80.50 \pm 15.87$ & $55.30 \pm 8.41$ & $96.90 \pm 14.38$ \\
\hline & & \multicolumn{2}{|r|}{ Baseline } & \multicolumn{2}{|c|}{ Co-location } & & & & \\
\hline \multicolumn{3}{|l|}{ Effect of demand (co-location) } & $57.41 * * *$ & \multicolumn{2}{|c|}{$131.26^{* * *}$} & & & & \\
\hline \multicolumn{2}{|l|}{ Effect of task type (co-location) } & & $25.20 * * *$ & \multicolumn{2}{|c|}{$32.01 * * *$} & & & & \\
\hline \multicolumn{2}{|l|}{ Demand $\times$ task (co-location) } & & $7.09 * * *$ & \multicolumn{2}{|c|}{$20.35 * * *$} & & & & \\
\hline \multicolumn{2}{|l|}{ Effect of configuration } & & $13.10 * * *$ & & & & & & \\
\hline \multicolumn{2}{|l|}{ Effect of configuration $\times$ task } & & $2.02^{*}$ & & & & & & \\
\hline \multicolumn{2}{|c|}{ Effect of configuration $\times$ task $\times$ demand } & & $2.54 * * *$ & & & & & & \\
\hline
\end{tabular}

$* p<0.05$

$* * * p<0.001$

operators seeing the greatest reductions (Stanton et al. 2017). Simultaneously, communication between the SOPs and TMAs have greatly increased. It appears that co-locating the SOPs and TMAs operators, who are dependent on each other for task-relevant information, has created a more cohesive social network and placed less demand on OPSO and SOC to act as information brokers between the sound room and picture room (Loft et al. 2015a, b).

When examining information composition, the effect of demand in the co-location configuration was also similar to that observed during baseline, with more interactions between information nodes observed in high demand (Stanton et al. 2017). However, in the high demand co-location configuration there were significantly more nodes and edges (despite less overall interactions), indicating greater connectivity between information. The opposite of this was observed during baseline, suggesting the new configuration has facilitated greater flexibility in terms of how information was structured when being passed between operators (Stanton et al. 2017). It also appears the co-location of task dependant operators has facilitated timely information transition as it is requested, rather than when an operator had the opportunity to pass information, removing production blocking mechanisms (Stanton et al. 2003). This is further verified by the fact that the density of the networks were significantly lower in the co-location. Information is no longer being repeatedly passed via multiple operators, in different orders and containing information that has not been requested. This highlights how the configuration of a team and supporting technology can greatly improve the effectiveness of overall team functionality (Stanton et al. 2015a, b; Espevik et al. 2006).

In the co-location configuration, the centrality of the TMA operators was significantly higher than in baseline, providing further verification of their increased importance to the social and information network composition (Stanton et al. 2017). However, the operator with the greatest centrality remained the OOW; this operator is required to interpret the range of information from different operators to make tactical decisions (Duryea et al. 2008). It should also be 
noted that the volume of communications between the junior operators (SOPS and TMAs) and their direct superiors (SOC and OPSO, respectively) remained comparable to baseline. This interaction is important for quality checking and supervision purposes, critical processes in team cognition and reducing the potential for loafing to occur (Fiore et al. 2010; Klein et al. 2006; Cooke et al. 2008; Simms and Nichols 2014; Suleiman and Watson 2008). This reveals that whilst changes to the structure of the task and information networks have occurred, some fundamental components have remained the same. A further example of this is the fact that there was no significant difference in the prevalence of information when compared to baseline (Stanton et al. 2017). The nodes with the highest sociometric status in the high- and low-demand co-location configurations were similar to those observed in baseline. This suggests that whilst the structure of information transition has changed the content has not, important information is being retained, but transition and structure is more efficient.

Once again when examining the effect of demand on task completion in the co-location configuration, findings were comparable to baseline, with more tasks being completed in high demand due to the greater number of contacts to manage (Stanton et al. 2017). When examining the type of tasks most frequently completed during the high demand scenario in the co-location configuration, it is clear that tasks relating to the development of a tactical picture (i.e. detecting contacts and generating solutions), were completed more frequently as this ensures a safe RTPD (Stanton 2014; citation). However, when directly comparing the co-location configuration to baseline a significantly greater number of tasks were completed overall in both high and low-demand scenarios. The co-location of operators dependant on each other for task-relevant information had increased overall productivity (Simms and Nichols 2014; Suleiman and Watson 2008; Stanton et al. 2003). When examining individual subtask completion, fundamental tasks (e.g. detecting, designation and generating solutions of contacts) remained similar during the low demand (when compared to baseline) but increased during the high demand, suggesting the new configuration has facilitated greater flexibility in productivity, with greater range in sub-task completion. This offers support for the fact that during baseline, productivity was blocked by the design of the system, which became apparent when capacity was being exceeded in the high demand scenarios (Stanton et al. 2003). The new configuration has facilitated greater flexibility in communication, structure of information transition and productivity (task completion) highlighting how the design of sociotechnical systems can be optimised to maximise human-technology-human interactions (Roco and Bainbridge 2003; Showalter 2005; Walker et al. 2009).

\section{Results for the reduced crew size}

\subsection{Social network analysis}

In the reduced crew size condition the average frequency of communications between operators in the command team varied depending on command team role and scenario demand (see Fig. 5). The overall composition of

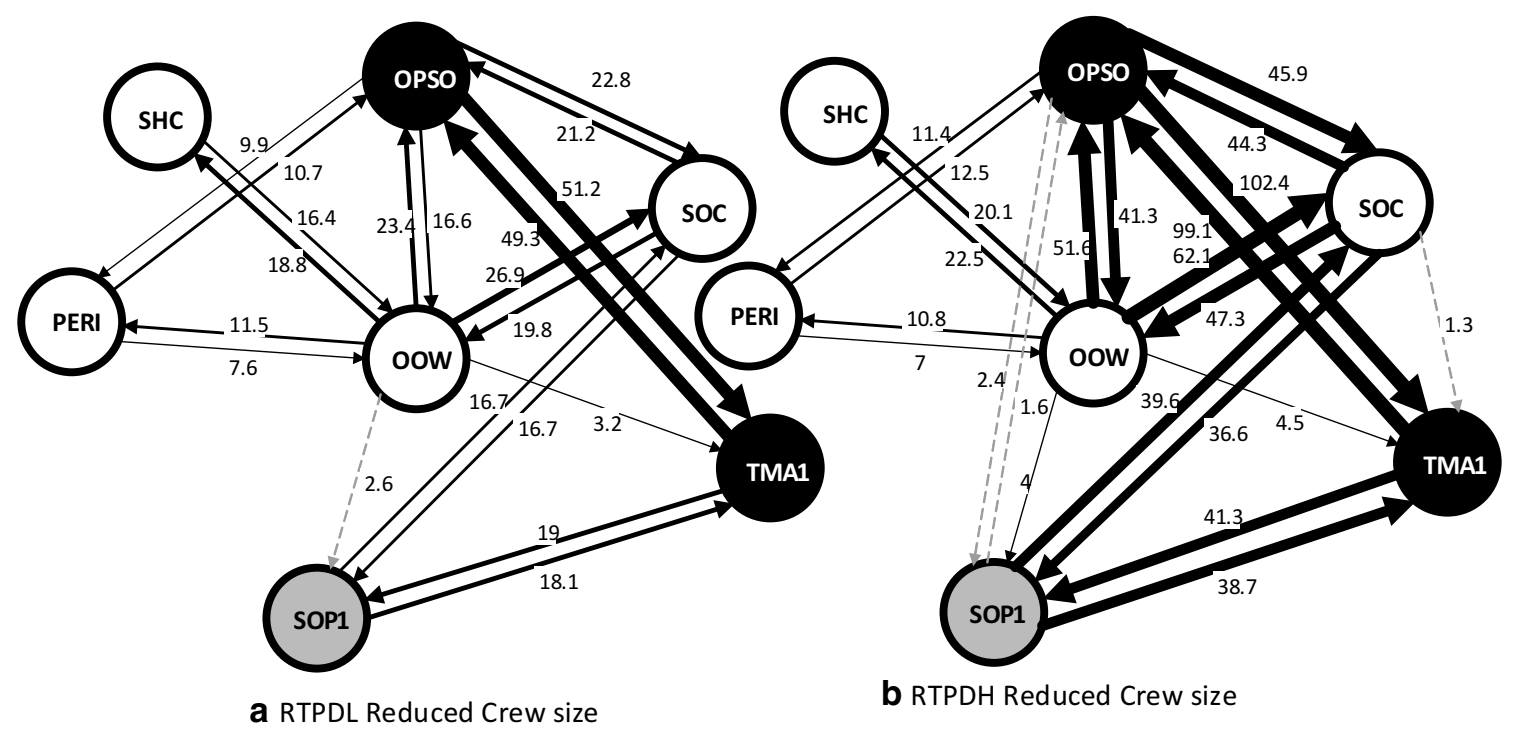

Fig. 5 Social network diagrams reduced crew size. OPSO and OOW had the largest volume of emissions and receptions of all operators, although the greatest number of communications was observed between OPSO and TMA1 (highlighted in black). The communication between SOP1 and TMA1 greatly increased when compared to baseline (highlighted in grey) 
Table 8 Social network metrics for whole network low- and high-demand RTPD baseline and reduced crew size condition

\begin{tabular}{|c|c|c|c|c|c|c|}
\hline & \multicolumn{4}{|l|}{ RTPD } & \multirow{3}{*}{$\begin{array}{l}\text { Effect of demand } \\
\text { reduced crew size }\end{array}$} & \multirow[t]{3}{*}{ Effect of crew size } \\
\hline & \multicolumn{2}{|c|}{ Baseline configuration } & \multicolumn{2}{|c|}{ Reduced crew size condition } & & \\
\hline & Low & High & Low & High & & \\
\hline Nodes & 9 & 9 & 7 & 7 & NA & NA \\
\hline Edges & $36.80 \pm 3.01$ & $36.50 \pm 4.93$ & $21.4 \pm 2.22$ & $22.10 \pm 1.52$ & 0.81 & $230.59 * * *$ \\
\hline Density & $0.51 \pm 0.04$ & $0.51 \pm 0.07$ & $0.51 \pm 0.05$ & $0.53 \pm 0.04$ & 0.80 & 0.51 \\
\hline Cohesion & $0.34 \pm 0.03$ & $0.35 \pm 0.03$ & $0.47 \pm 0.06$ & $0.48 \pm 0.04$ & 0.37 & $80.19 * * *$ \\
\hline Total interactions & $663.80 \pm 206.32$ & $816.10 \pm 221.10$ & $418.90 \pm 69.33$ & $749.50 \pm 124.79$ & $8.90 * * *$ & $6.12 *$ \\
\hline
\end{tabular}

$* p<0.05$

$* * * \quad p<0.001$

both networks is similar, however the volume of interactions between operators increased during the high demand reduced crew size RTPD scenarios.

\subsection{Whole network metrics}

The total interactions $\left(t_{9}=-8.90, p<0.05, r=0.95\right)$ statistically significantly increased in the high-demand reduced crewsize condition configuration. The total number of edges $\left(F_{1,18}=230.59, p<0.05, \eta_{\mathrm{p}}^{2}=0.93\right)$, total interactions $\left(F_{1,18}=6.12, p<0.05, \dot{\eta}_{\mathrm{p}}^{2}=0.25\right)$, and cohesion $\left(F_{1,18}=80.19\right.$, $\left.p<0.01, \hat{\eta}_{\mathrm{p}}^{2}=0.82\right)$ of the entire networks were statistically significantly affected by configuration type. This indicates that the structure of the networks fundamentally changed as a result of the reduced crew size, but such differences were effected by demand (see Table 8; Fig. 5).

\section{Nodal metrics}

\subsection{Emissions}

In the reduced crew size condition the total emissions of each node were statistically significantly affected by scenario demand $\left(F_{1,63}=248.77, p<0.01, \hat{\eta}_{\mathrm{p}}^{2}=0.80\right)$ and operator role $\left(F_{6,63}=86.01, p<0.01, \eta_{\mathrm{p}}^{2}=0.89\right)$. The interaction of scenario demand and role also statistically significantly affected total node emissions $\left(F_{6,63}=19.19\right.$, $\left.p<0.01, \eta_{\mathrm{p}}^{2}=0.65\right)$. When examining the effect of scenario demand post hoc analysis revealed overall, emissions were statistically significantly higher $(p<0.05)$ in the high demand RTPD condition than the low-demand condition. All operators except PERI and SHC had statistically significantly more emissions in the high demand condition than the low-demand condition. When examining the effect of role post hoc analysis revealed that OPSO had statistically significantly higher $(p<0.05)$ emissions than all other operators (see Table 9; Fig. 5). OOW had statistically significantly $(p<0.05)$ more emissions than all operators except OPSO and TMA1. TMA1 had statistically significantly $(p<0.05)$ more emissions than all operators except OPSO, OOW and SOC. When examining the interaction between demand and role post hoc analysis revealed that OPSO had statistically significantly $(p<0.05)$ more emissions than OOW in the high demand condition but not in the low-demand condition.

The total emissions of each node were not statistically significantly affected by reduced crew size $\left(F_{1,126}=1.87\right.$, $p>0.05)$. The interaction of reduced crew size and role statistically significantly affected total emissions $\left(F_{6,126}=11.67, p<0.01, \eta_{\mathrm{p}}^{2}=0.36\right)$. A non-significant trend was observed for the interaction of reduced crew size, role and demand on emissions $\left(F_{6,126}=1.24\right.$, $p=0.06)$. Post hoc analysis revealed TMA1 had statistically significantly $(p<0.05)$ more emissions in reduced crew size condition than baseline condition. SOC and OPSO had statistically significantly $(p<0.05)$ less emissions in reduced crew size condition compared to baseline.

\subsection{Receptions}

In the reduced crew size condition the total receptions of each node were significantly affected by scenario demand $\left(F_{1,63}=236.65, p<0.01, \dot{\eta}_{\mathrm{p}}^{2}=0.79\right)$ and operator role $\left(F_{6,63}=90.27, p<0.01, \hat{\eta}_{\mathrm{p}}^{2}=0.90\right)$. The interaction of scenario demand and role also statistically significantly affected total node receptions $\left(F_{6,63}=19.87, p<0.01\right.$, $\left.\dot{\eta}_{\mathrm{p}}^{2}=0.65\right)$. When examining the effect of scenario demand post hoc analysis revealed overall, receptions were statistically significantly higher $(p<0.05)$ in the high demand 


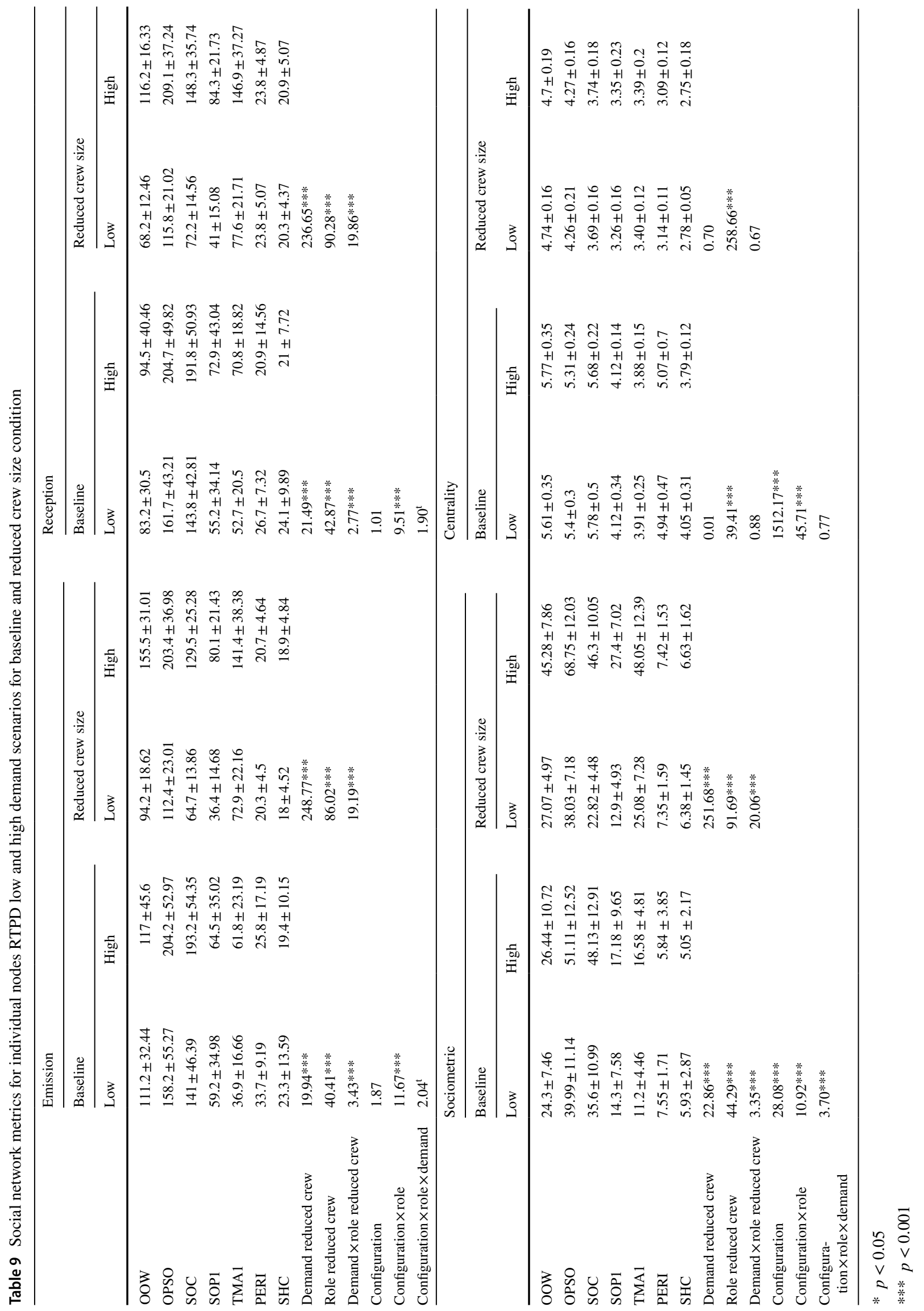


RTPD condition than the low-demand condition. All operators had statistically significantly $(p<0.05)$ more receptions in the high-demand condition compared to the low-demand condition except PERI and SHC. When examining the effect of role post hoc analysis revealed that OPSO had statistically significantly higher $(p<0.05)$ receptions than all other operators (see Table 9; Fig. 5). SOC, OOW and TMA1 had statistically significantly $(p<0.05)$ more receptions than all operators (except OPSO), although no significant difference was observed between these operators.

The total receptions of each node were not statistically significantly affected by reduced crew size $\left(F_{1,126}=1.87\right.$, $p>0.05)$. The interaction of reduced crew size and role statistically significantly affected total receptions $\left(F_{6,126}=11.62, p<0.05, \dot{\eta}_{\mathrm{p}}^{2}=0.36\right)$. A non-significant trend was observed for the interaction of reduced crew size, role and demand $\left(F_{6,126}=1.90, p=0.08\right)$. Post hoc analysis revealed OPSO and SOC had statistically significantly $(p<0.05)$ less receptions in the reduced crew size condition than baseline. TMA1 had statistically significantly $(p<0.05)$ more receptions in the reduced crew size condition compared to baseline.

\subsection{Sociometric status}

In the reduced crew size condition the sociometric status of each node was significantly affected by scenario demand $\left(F_{1,63}=251.68, p<0.01, \dot{\eta}_{\mathrm{p}}^{2}=0.80\right)$ and operator role $\left(F_{6,63}=91.69, p<0.01, \dot{\eta}_{\mathrm{p}}^{2}=0.90\right)$. The interaction of scenario demand and role also statistically significantly affected sociometric status $\left(F_{6,63}=20.06, p<0.01, \dot{\eta}_{\mathrm{p}}^{2}=0.66\right)$. When examining the effect of scenario demand post hoc analysis revealed overall sociometric status was statistically significantly higher $(p<0.05)$ in the higher demand RTPD condition than the low-demand condition. All operators had statistically significantly $(p<0.05)$ higher sociometric status in the high-demand condition compared to the low demand except PERI and SHC. When examining the effect of operator role post hoc analysis revealed OPSO had statistically significantly $(p<0.05)$ higher sociometric status than all other operators. OOW, SOC and TMA1 had statistically significantly $(p<0.05)$ higher sociometric status than all operators (except OPSO) although no significant difference was observed between these operators.

The sociometric status of each node was statistically significantly affected by reduced crew size $\left(F_{1,126}=28.08\right.$, $\left.p<0.01, \dot{\eta}_{\mathrm{p}}^{2}=0.18\right)$ and the interaction of reduced crew size, role and demand $\left(F_{6,126}=3.73, p<0.05, \dot{\eta}_{\mathrm{p}}^{2}=0.15\right)$. The interaction of reduced crew size and role statistically significantly affected sociometric status $\left(F_{6,126}=10.91, p<0.01\right.$, $\left.\hat{\eta}_{\mathrm{p}}^{2}=0.34\right)$. Post hoc analysis revealed that sociometric status statistically significantly $(p<0.05)$ increased in reduced crew size condition compared to baseline. Post hoc analysis revealed OOW and TMA1 had statistically significantly $(p<0.05)$ higher sociometric status in reduced crew size condition than in the baseline condition. Further analysis revealed OOW and OPSO had statistically significantly $(p<0.05)$ higher sociometric status in reduced crew size condition high demand than baseline high demand, but not in the low demand conditions.

\subsection{Centrality}

In the reduced crew size condition the centrality of each node was not statistically significantly affected by scenario demand $\left(F_{1,63}=0.8, p>0.05\right)$ or the interaction between scenario demand and role $\left(F_{6,63}=0.67, p>0.05\right)$. Centrality was significantly affected by operator role $\left(F_{6,63}=165.17\right.$, $\left.p<0.01, \hat{\eta}_{\mathrm{p}}^{2}=0.94\right)$. When examining the effect of role post hoc analysis revealed OOW had statistically significantly $(p<0.05)$ higher centrality than all operators. OPSO had statistically significantly higher centrality than all operators (except OOW). SOC had statistically significantly $(p<0.05)$ higher centrality than all operators (except OPSO and OOW). SOP1 and TMA1 had statistically significantly $(p<0.05)$ higher centrality than SHC and PERI, although no significant difference was observed between these operators.

The centrality of each node was statistically significantly affected by the reduced crew size $\left(F_{1,126}=1512.17, p<0.01\right.$, $\left.\dot{\eta}_{\mathrm{p}}^{2}=0.92\right)$ but not by the interaction of crew size, role and demand $\left(F_{6,126}=0.77, p>0.05\right)$. The interaction of crew size and role statistically significantly affected centrality $\left(F_{6,126}=45.71, p<0.01, \dot{\eta}_{\mathrm{p}}^{2}=0.69\right)$. Post hoc analysis revealed that centrality statistically significantly $(p<0.05)$ decreased in reduced crew size condition compared to baseline. Post hoc analysis revealed all operators had statistically significantly $(p<0.05)$ lower centrality in reduced crew size condition than in the baseline condition.

\subsection{Information network analysis}

In the reduced crew size condition the structure of the information networks was relatively consistent in both high- and low-demand RTPD scenarios. However, the volume of information passed was greater in high demand, but differences in relationships can be observed depending on information type (see Fig. 6; Table 10). 


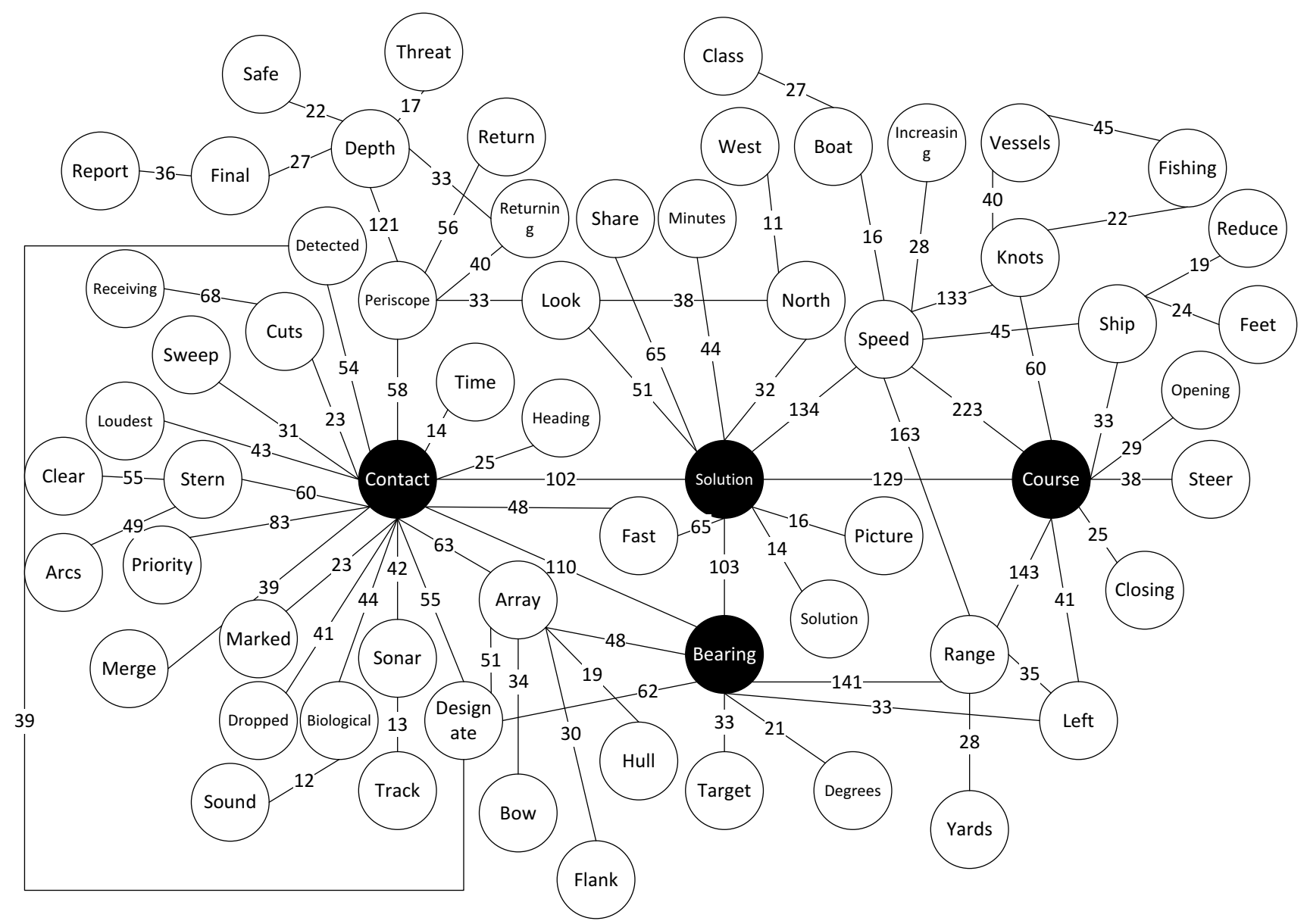

Fig. 6 Information network RTPD high demand reduced crew size configuration. The information nodes contact, bearing, solution and course (highlighted in black) were the most connected information pieces, which was similar to baseline and co-location with a reduced crew size

\subsection{Whole network metrics}

In the reduced crew size configuration statistically significantly more emissions $\left(t_{9}=2.57, p<0.05, d=1.78\right)$, nodes $\left(t_{9}=2.91\right.$, $p<0.05, d=1.47)$ and edges $\left(t_{9}=3.12, p<0.05, d=1.45\right)$, but lower overall diameter $\left(t_{9}=3.00, p<0.05, d=2.57\right)$ in the high-demand condition compared to low demand (see Table 11), indicating that the overall structure of information varied based upon scenario demand. Configuration statistically significantly affected the number of nodes $\left(F_{1,18}=15.55\right.$, $\left.p<0.01, \hat{\eta}_{\mathrm{p}}^{2}=0.46\right)$, and network density $\left(F_{1,18}=22.02\right.$, $\left.p<0.01, \dot{\eta}_{\mathrm{p}}^{2}=0.55\right)$. A statistically significant interaction between configuration and demand was observed for total nodes $\left(F_{1,18}=5.18, p<0.01, \dot{\eta}_{\mathrm{p}}^{2}=0.22\right)$, edges $\left(F_{1,18}=5.69\right.$, $\left.p<0.01, \dot{\eta}_{\mathrm{p}}^{2}=0.24\right)$, diameter $\left(F_{1,18}=9.53, p<0.01, \dot{\eta}_{\mathrm{p}}^{2}=0.35\right)$ and total emissions $\left(F_{1,18}=7.53, p<0.01, \hat{\eta}_{\mathrm{p}}^{2}=0.30\right)$.

The overall network density was statistically significantly $(p<0.05)$ lower in the reduced crew size configuration compared to baseline but the number of nodes was statistically significantly $(p<0.05)$ higher in the reduced crew size configuration compared to baseline. The number of nodes were statistically significantly higher in the high demand reduced crew size configuration compared to baseline. The number of edges were statistically significantly $(p<0.05)$ lower in the low demand reduced crew size configuration compared to baseline, but statistically significantly $(p<0.05)$ higher in the high demand condition. The diameter of the networks were statistically significantly $(p<0.05)$ higher in the low demand reduced crew size configuration compared to baseline. The total emissions were statistically significantly $(p<0.05)$ lower in the reduced crew size low-demand configuration compared to baseline.

\section{Nodal metrics}

\subsection{Emissions}

In the reduced crew size configuration the total emissions of each node were statistically significantly affected by scenario 


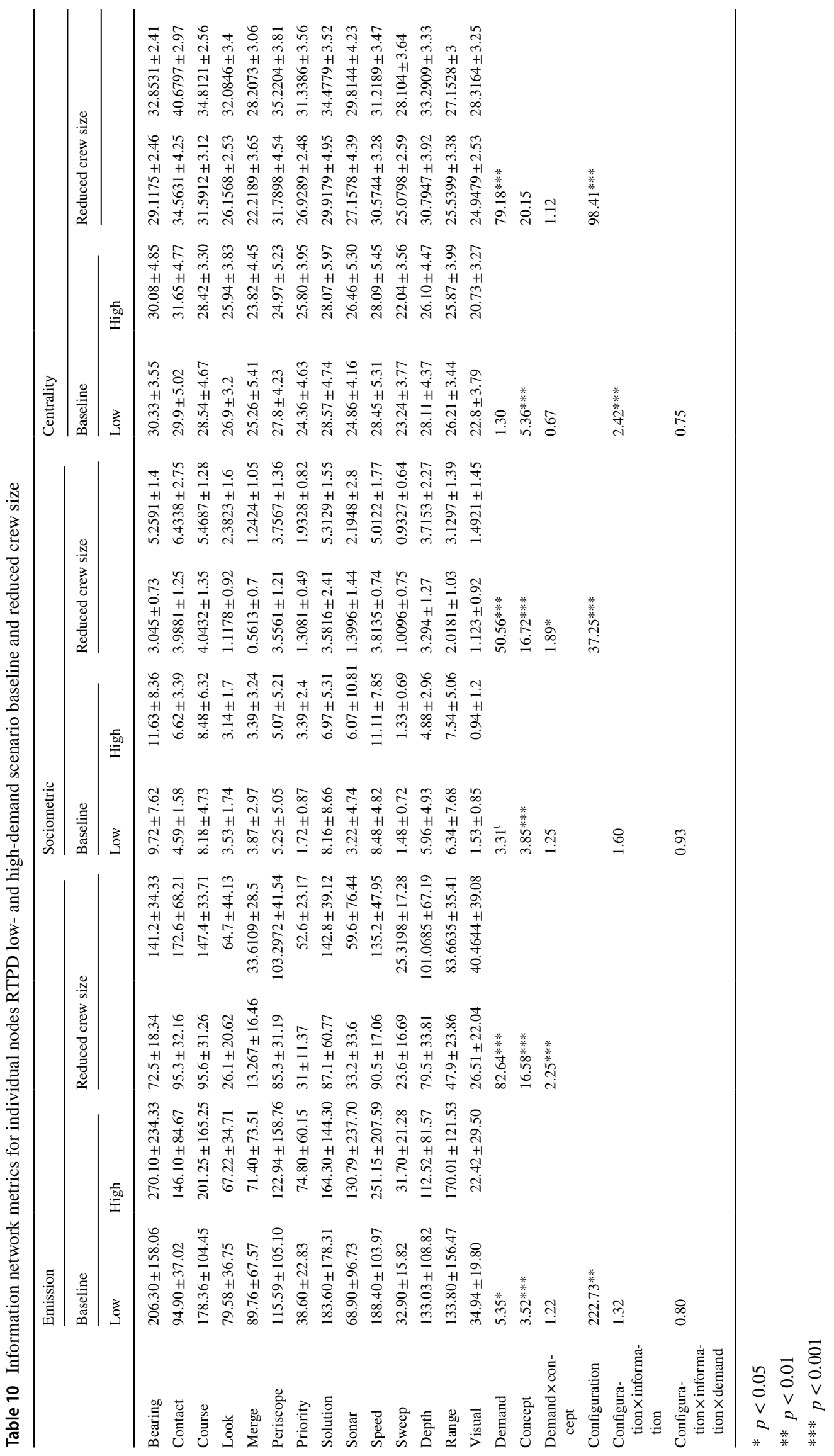


Table 11 Information network metrics RTPD baseline and reduced crew size

\begin{tabular}{|c|c|c|c|c|c|c|c|}
\hline & \multicolumn{2}{|l|}{ Baseline } & \multicolumn{2}{|l|}{ Reduced crew size } & \multirow[t]{2}{*}{ Effect of demand } & \multirow{2}{*}{$\begin{array}{l}\text { Effect of } \\
\text { configura- } \\
\text { tion }\end{array}$} & \multirow{2}{*}{$\begin{array}{l}\text { Configura- } \\
\text { tion } \times \text { demand }\end{array}$} \\
\hline & Low & High & Low & High & & & \\
\hline Nodes & $45.60 \pm 5.10$ & $44.40 \pm 6.46$ & $47.8 \pm 5.37$ & $54.7 \pm 4.11$ & $2.91 *$ & $15.55^{* * *}$ & $5.18^{*}$ \\
\hline Edges & $702.10 \pm 330.28$ & $644.80 \pm 357.54$ & $552.8 \pm 112.4$ & $782 \pm 168.92$ & $3.12 *$ & 0.004 & $5.69 *$ \\
\hline Density & $0.49 \pm 0.15$ & $0.49 \pm 0.19$ & $0.24 \pm 0.03$ & $0.26 \pm 0.05$ & 1.11 & $22.02 * * *$ & 0.1 \\
\hline Diameter & $3.30 \pm 0.82$ & $3.5 \pm 0.53$ & $4.2 \pm 0.92$ & $3.2 \pm 0.42$ & $3.00 *$ & 1.47 & $9.53 * *$ \\
\hline Total emissions & $2412.10 \pm 1424.21$ & $2898.90 \pm 2620.68$ & $1556.99 \pm 408.8$ & $2305.16 \pm 782.44$ & $2.57 *$ & 0.89 & $7.53 *$ \\
\hline
\end{tabular}

$* p<0.05$

$* * p<0.01$

$* * * \quad p<0.001$

demand $\left(F_{1,126}=82.64, p<0.01, \hat{\eta}_{\mathrm{p}}^{2}=0.40\right)$ and concept type $\left(F_{13,126}=16.59, p<0.01, \hat{\eta}_{\mathrm{p}}^{2}=0.63\right)$. A statistically significant $\left(F_{13,126}=2.52, p<0.01, \dot{\eta}_{\mathrm{p}}^{2}=0.19\right)$ interaction between demand and concept was also observed. Emissions were statistically significantly higher $(p<0.05)$ in the highdemand RTPD condition than the low-demand condition. Further analysis revealed bearing, contact, course, periscope, speed, depth and solution had statistically significantly $(p<0.05)$ more emissions than all other information. Emissions of bearing, contact, course and solution were statistically significantly $(p<0.05)$ higher in the high demand condition than the low demand condition. The total emissions of each node were statistically significantly affected by configuration type $\left(F_{1,252}=22.73, p<0.01, \hat{\eta}_{\mathrm{p}}^{2}=0.08\right)$. The total number of emissions was statistically significantly $(p<0.05)$ lower in the reduced crew size configuration.

\subsection{Receptions}

In the reduced crew size configuration the total receptions of each node were statistically significantly affected by scenario demand $\left(F_{1,126}=82.64, p<0.01, \dot{\eta}_{\mathrm{p}}^{2}=0.40\right)$ and concept type $\left(F_{13,126}=16.59, p<0.01, \dot{\eta}_{\mathrm{p}}^{2}=0.63\right)$. A statistically significant $\left(F_{13,126}=2.52, p<0.01, \eta_{\mathrm{p}}^{2}=0.19\right)$ interaction between demand and concept was also observed. Receptions were statistically significantly higher $(p<0.05)$ in the high demand RTPD condition than the low-demand condition. Further analysis revealed bearing, contact, course, periscope, speed, depth and solution had statistically significantly $(p<0.05)$ more receptions than all other information. Receptions of bearing, contact, course and solution were statistically significantly $(p<0.05)$ higher in the high demand condition than the low-demand condition. The total receptions of each node were statistically significantly affected by configuration type $\left(F_{1,252}=22.72, p<0.01, \hat{\eta}_{\mathrm{p}}^{2}=0.08\right)$. The total number of receptions was statistically significantly $(p<0.05)$ lower in the reduced crew size configuration.

\subsection{Sociometric status}

In the reduced crew size configuration the sociometric status of each node was statistically significantly affected by scenario demand $\left(F_{1,126}=82.64, p<0.01, \dot{\eta}_{\mathrm{p}}^{2}=0.40\right)$ and concept type $\left(F_{13,126}=16.72, p<0.01, \hat{\eta}_{\mathrm{p}}^{2}=0.63\right)$. A statistically significant $\left(F_{13,126}=1.89, p<0.05, \dot{\eta}_{\mathrm{p}}^{2}=0.16\right)$ interaction between demand and concept was also observed. Sociometric status was statistically significantly higher $(p<0.05)$ in the high demand RTPD condition than the low-demand condition. Further analysis revealed bearing, contact, course, periscope, speed, depth and solution had statistically significantly $(p<0.05)$ more emissions than all other information. Bearing and contact had statistically significantly $(p<0.05)$ higher sociometric status in the high demand condition compared to the low-demand condition. The sociometric status of each node was statistically significantly affected by configuration type $\left(F_{1,252}=37.25, p<0.01, \dot{\eta}_{\mathrm{p}}^{2}=0.13\right)$.

\subsection{Centrality}

In the reduced crew size configuration the centrality of each node was statistically significantly affected by scenario demand $\left(F_{1,126}=79.18, p<0.01, \eta_{\mathrm{p}}^{2}=0.39\right)$ and concept type $\left(F_{13,126}=20.15, p<0.01, \hat{\eta}_{\mathrm{p}}^{2}=0.68\right)$. Centrality was statistically significantly $(p<0.05)$ higher in the high demand condition. Further analysis revealed that contact had statistically significantly $(p<0.05)$ higher centrality than all information. The centrality of each node was statistically significantly affected by configuration type $\left(F_{1,252}=98.41, p<0.01, \tilde{\eta}_{\mathrm{p}}^{2}=0.28\right)$. A statistically significant $\left(F_{13,252}=2.42, p<0.01, \eta_{\mathrm{p}}^{2}=0.11\right)$ interaction between configuration and information was also observed. Centrality was statistically significantly $(p<0.05)$ higher in the reduced crew size configuration compared to 

completion RTPD scenarios baseline and reduced crew size
Table 12 Frequency of task

\begin{tabular}{|c|c|c|c|c|}
\hline \multirow[t]{3}{*}{ Demand } & \multicolumn{4}{|l|}{ RTPD } \\
\hline & \multicolumn{2}{|l|}{ Baseline } & \multicolumn{2}{|c|}{ Reduced crew size } \\
\hline & Low & High & Low & High \\
\hline Detect sonar contacts & $4 \pm 1.89$ & $8.7 \pm 4.22$ & $2.6 \pm 1.35$ & $10.8 \pm 3.71$ \\
\hline Designate sonar contacts & $3.3 \pm 1.64$ & $7.7 \pm 4.85$ & $2.6 \pm 1.35$ & $10 \pm 3.56$ \\
\hline Classify sonar contacts & $3.8 \pm 1.87$ & $10.5 \pm 4.3$ & $1.8 \pm 1.4$ & $7.8 \pm 4.42$ \\
\hline Sonar speed estimates & $5.4 \pm 2.27$ & $10.9 \pm 5.67$ & $2.9 \pm 1.79$ & $7.7 \pm 2.98$ \\
\hline Sonar course estimates & $1.2 \pm 1.23$ & $4.9 \pm 2.13$ & $3.5 \pm 1.84$ & $4.6 \pm 3.47$ \\
\hline Check cuts & $2.4 \pm 1.84$ & $3.9 \pm 1.52$ & $2.8 \pm 1.75$ & $6 \pm 3.71$ \\
\hline Sonar merges & $3.4 \pm 1.35$ & $2.8 \pm 1.81$ & $2.8 \pm 1.62$ & $5.4 \pm 3.24$ \\
\hline Sonar solution & $4.6 \pm 1.96$ & $10.7 \pm 3.53$ & $4.1 \pm 0.32$ & $10.9 \pm 1.85$ \\
\hline Refine solutions & $4.2 \pm 3.58$ & $5.1 \pm 3.63$ & $3.9 \pm 3.38$ & $3.8 \pm 3.68$ \\
\hline Change submarine parameters & $4.4 \pm 2.46$ & $4.3 \pm 2.06$ & $5.4 \pm 1.35$ & $5.6 \pm 2.07$ \\
\hline Raise periscope & $1 \pm 0$ & $0.8 \pm 0.42$ & $1 \pm 0$ & $1 \pm 0$ \\
\hline Complete sweep & $1.8 \pm 0.63$ & $0.8 \pm 0.42$ & $1.4 \pm 0.52$ & $1.3 \pm 0.67$ \\
\hline Detect visual contacts & $1.7 \pm 0.95$ & $1.4 \pm 1.07$ & $3.7 \pm 1.06$ & $4.2 \pm 2.04$ \\
\hline Total tasks completed & $48.20 \pm 9.07$ & $80.50 \pm 15.87$ & $49.10 \pm 7.09$ & $87.80 \pm 19.89$ \\
\hline Effect of demand & $57.41 * * *$ & & $125.33 * * *$ & \\
\hline Effect of task type & $25.20 * * *$ & & $20.38 * * *$ & \\
\hline Demand $\times$ task & $7.09 * * *$ & & $15.45 * * *$ & \\
\hline Configuration & 1.71 & & & \\
\hline Configuration $\times$ task & $2.77 * * *$ & & & \\
\hline Configuration $\times$ task $\times$ demand & $1.65^{*}$ & & & \\
\hline
\end{tabular}

$* p<0.05$

$* * * p<0.001$

baseline. The centrality of contact was statistically significantly $(p<0.05)$ higher in the reduced crew size configuration compared to baseline.

\subsection{Task network analysis}

The type of tasks completed by the command team were the same during baseline and the reduced crew size configuration (for both high and low-demand scenarios) as the fundamental task completed by operators did not change. However, the frequency of task completion was effected (as with the co-location full team comparison to baseline).

In the reduced crew size condition the frequency of task completion was statistically significantly affected by scenario demand $\left(F_{1,189}=125.33, p<0.01, \hat{\eta}_{\mathrm{p}}^{2}=0.40\right)$ and task type $\left(F_{20,189}=20.39, p<0.01, \dot{\eta}_{\mathrm{p}}^{2}=0.68\right)$. A statistically significant interaction $\left(F_{20,189}=15.45, p<0.01, \dot{\eta}_{\mathrm{p}}^{2}=0.62\right)$ between scenario demand and task type was also observed. Post hoc analysis revealed the frequency of tasks completion was statistically significantly higher $(p<0.05)$ in the high demand condition than the lowdemand condition. The tasks detecting, designating, classifying generating speed estimates and generating solutions for sonar contacts were completed statistically significantly $(p<0.05)$ more in the high demand condition than the lowdemand condition. The tasks detecting, designating and generating sonar solutions were completed statistically significantly more than all periscope based tasks (e.g. visual detection, range and classify). The tasks classify sonar contacts, generate speed solutions and change own submarine parameters were completed more frequently than all other tasks except detect and designate visual contacts (and those already mentioned, see Table 12).

The frequency of task completion was not statistically significantly affected by crew size $\left(F_{1,378}=1.47, p>0.05\right)$. It was statistically significantly affected by the interaction of crew size and task type $\left(F_{20,378}=2.77, p<0.01, \dot{\eta}_{\mathrm{p}}^{2}=0.13\right)$ and the interaction of crew size, task type and demand $\left(F_{20,378}=1.65, p<0.05, \hat{\eta}_{\mathrm{p}}^{2}=0.08\right)$. Further analysis revealed the tasks of detecting visual and designating visual were completed statistically significantly $(p<0.05)$ more frequently in reduced crew size condition than in baseline (in both the low and high demand conditions). The tasks of detecting and designating sonar contacts were completed statistically significantly $(p<0.05)$ more frequently in the 
high demand reduced crew size configuration than all other conditions.

\section{Discussion for the reduced crew size}

The effect of scenario demand in the reduced crew size configuration was similar to what was observed for the full co-located team study and baseline. The command team communicated more frequently, with greater connectivity of information structure and a number of tasks being completed (Stanton et al. 2017). The similarities of information prevalence between baseline and the co-location configuration were also observed with a reduced crew size. Furthermore, as with the full crew in co-location the differences between the low and high demand scenarios were much greater, further highlighting that the new configuration appears to have increased capacity, but that capacity is only utilised when it is operationally relevant. This shows that, even with a reduced crew size, the command team had additional capacity when completing the low-demand scenarios. This can provide insights into when economic savings could be made (in terms of manning), but perhaps more importantly how data from new sensors and instruments might best be integrated into the command space, as the removed operators may have the capacity to process additional sensor information (Hamburger et al. 2011; Mankins 2009; Allender 2000).

When comparing the co-location configuration to baseline, the volume of communications between OPSO and TMA1 increased by the greatest amount, suggesting that OPSO was more involved in the TMA process rather than just delegating workload between operators (Stanton et al. 2017). This is verified by the fact that the sociometric status of OPSO increased far more than any operator when compared to baseline (particularly in high demand). A further contributing factor to this is the increased communication between OPSO and OOW, to assist with confirmation of the tactical picture (Roberts and Stanton 2018; Duryea et al. 2008). This highlights that whilst the co-location configuration has appeared to increased capacity it has placed additional cognitive load on OPSO (Roberts and Cole 2018; Baddeley 2000). This is in spite of the fact that the number of communications observed between SOP1 and TMA1 significantly increased, suggesting that the co-location of these operators facilitated coping with the additional demand resulting from reduced crew size. In the baseline configuration, there was a reliance on OPSO to act as an information broker between the sound and picture room (Stanton et al. 2017; Loft et al. 2015a, b).

It appears that a difference in command team strategy was observed in terms of information exchange with reduced crew size. In the low-demand conditions the sociometric status of all operators was more even, suggesting that the tactical picture was developed organically in a bottom-up fashion (Roberts and Stanton 2018). However, in the higher demand scenarios the senior operators (OOW, OPSO and SOC) had much higher sociometric status, suggesting these operators were more involved in building the tactical picture in a top-down fashion. This may be due to the fact that the command team had reached workload capacity so was required to prioritise particular contacts (as the whole picture could not be processed) resulting in more communication load on senior operators (Duryea et al. 2008). This is further validated by the fact that a number of sub-tasks were completed more frequently in the reduced crew size configuration. The total number of sonar detections and designations increased (although not significantly), indicating the command teams needed to be aware of all contacts. However, the number of speed estimates, classifications and solutions decreased suggesting the command team were being required to prioritise which contacts to further process (Stanton 2014). Despite this, no significant differences in total task completion was observed between the reduced crew size and baseline, suggesting the co-location had increased capacity to cope with a reduced crew size. Although, smaller crew sizes have been associated with greater productivity as the potential to 'loaf' is reduced (Alnuaimi et al. 2010).

\section{Summary and conclusions}

The current work compared the functionality of submarine command teams completing a RTPD in a representation of a contemporary operational control room configuration (baseline), a co-location configuration and reduced crew size. The co-location configuration improved the efficiency of communications between operators, resulting in a change in structure of information transition and an increase of overall productivity with more tasks being completed compared to baseline (Stanton et al. 2017). The co-location configuration afforded greater flexibility in operational capacity with more pronounced differences between low and high demand scenarios also observed. Furthermore, the co-location configuration improved efficiency to facilitate coping with a reduced crew size, resulting in similar productivity to what was observed during baseline (Huddlestone and Harris 2017; Schutte 2017). The co-location of operator's dependent on each other for task-relevant information reduced loafing which may have occurred due to production blocking resulting from engineering limitations observed in the baseline scenarios (Simms and Nichols 2014; Suleiman and Watson 2008; Stanton et al. 2003; Binns 2008; Burcher and Rydill 1995). These results offer insight into how sociotechnical systems can be optimised to obtain maximal utility from future technological advancements (Hamburger et al. 2011; 
Mankins 2009; Roco and Bainbridge 2003; Showalter 2005; Walker et al. 2008). They also offer insights into where economic savings might be gained in such systems and where additional capacity might be found to cope with additional data processing requirements in the control room from technology upgrades and sensor advancements (Brynjolfsson and Hitt 2000; Devaraj and Kohli 2003; Hewish 2002).

The findings from this study show that co-location has benefits, but there are potential drawbacks to consider. First is the need to redesign control rooms that enable this reconfiguration to take place (Stanton et al. 2010). As Stanton et al. (2010) have shown, changing one aspect of the control room has knock-on effects to other aspects. Second, the size of the control room has to accommodate the more personnel, so merging the sound room and control room will mean finding a new location on board a submarine that can house the increased personnel. This is not a problem for most landbased control rooms. Finally, the reduced crew condition did stretch the team to their workload capacity in the higher demand scenario, to their point where they were prioritising contacts. This meant that there was no additional spare capacity to accommodate changes in priorities.

The current results offer insight into the development of submarine control rooms but also for wider control room design across many domains (Rudisill 2000; Bruce et al. 1998; Stanton et al. 2016; Santos et al. 2008). The removal of historic engineering based constraints offers avenues for improvements (Binns 2008; Burcher and Rydill 1995). However, a degree of caution is warranted as technological support (e.g. noise cancelling headphones) requires further investigation to examine the impact of such technology on actual task performance (Arrabito et al. 2005). Moreover, the economic savings associated with reducing crew size does not always consider the wider tasks undertaken by command team operators that would still require completion (e.g. cleaning, maintenance and extremely high workload situations). A primary consideration when reviewing reduced crewing should be an examination of overall sociotechnical system safety (Salotti et al. 2014; Huddlestone and Harris 2017; Schutte 2017). Therefore, future work should examine how the changes to functionality detailed in the current studies impact on accuracy of tactical pictures, decision making and overall submarine safety and maintenance.

Acknowledgements This work was supported in part by the Human Sciences Domain of the UK Ministry of Defence Scientific Research Pro-gramme, contract TIN3.113. Any views expressed are those of the authors and do not necessarily represent those of the Ministry of Defence or any other UK government department.

OpenAccess This article is distributed under the terms of the Creative Commons Attribution 4.0 International License (http://creativeco mmons.org/licenses/by/4.0/), which permits unrestricted use, distribution, and reproduction in any medium, provided you give appropriate credit to the original author(s) and the source, provide a link to the Creative Commons license, and indicate if changes were made.

\section{References}

Allender L (2000) Modeling human performance: impacting system design, performance, and cost. Simul Ser 32(3):139-144

Alnuaimi OA, Robert LP, Maruping LM (2010) Team size, dispersion, and social loafing in technology-supported teams: a perspective on the theory of moral disengagement. J Manag Inf Syst 27(1):203-230

Arrabito GR, Cooke BE, McFadden SM (2005) Recommendations for enhancing the role of the auditory modality for processing sonar data. Appl Acoust 66(8):986-1005

Baddeley A (2000) The episodic buffer: a new component of working memory? Trends Cogn Sci 4:417-423

Binns SD (2008) Meeting the current challenge of designing high capability SSKS. Warship. Paper on BMT's new SSK design, Vidar-36 presented at the UDT Pacific 2008 conference in Sydney, Australia. https://www.bmtdsl.co.uk/media/6097771/BMTDSL-Desig ning-SSKs-Vidar-Confpaper-UDTPacific-Oct08.pdf. Accessed 9 Feb 2019

Bruce S, Rice C, Hepp R (1998) Design and test of military cockpits. In: aerospace conference, 1998 IEEE, vol 3, pp 5-14

Brynjolfsson E, Hitt LM (2000) Beyond computation: information technology, organizational transformation and business performance. J Econ Perspect 14(4):23-48

Brynjolfsson E, McAfee A (2011) Race against the machine. Digital Frontier Press, Lexington, Mass, USA

Burcher R, Rydill LJ (1995) Concepts in submarine design, vol 2. Cambridge University Press, Cambridge

Carletta J, Anderson AH, McEwan R (2000) The effects of multimedia communication technology on non-collocated teams: a case study. Ergonomics 43(8): 1237-1251

Cooke NJ, Gorman JC, Kiekel PA (2008) Communication as teamlevel cognitive processing. In: Letsky MP, Warner NW, Fiore S, Smith CAP (eds) Macrocognition in teams: theories and methodologies. Ashgate Publishing Ltd., Aldershot, pp 51-64

Devaraj S, Kohli R (2003) Performance impacts of information technology: is actual usage the missing link? Manag Sci 49(3):273-289

Duryea DM, Lindstrom CE, Sayegh R (2008) Submarine imaging systems: developing improved capabilities and technologies. In: SPIE defence and security symposium proceedings. pp 69430X-69430X, April, 2006, Florida, USA

Espevik R, Johnsen BH, Eid J, Thayer JF (2006) Shared mental models and operational effectiveness: effects on performance and team processes in submarine attack teams. Mil Psychol 18(S):S23

Fiore SM, Smith-Jentsch KA, Salas E, Warner N, Letsky M (2010) Towards an understanding of macrocognition in teams: developing and defining complex collaborative processes and products. Theor Issues Ergon Sci 11(4):250-271

Fiore SM, Graesser A, Greiff S (2018) Collaborative problem-solving education for the twenty-first century work force. Nature Human. Behaviour. https://doi.org/10.1038/s41562-018-0363-y

Hamburger P, Miskimens D, Truver S (2011) It is not just hardware and software, anymore! Human systems integration in US submarines. Nav Eng J 123(4):41-50

Hewish M (2002) Submarines to cast off their shackles take on new roles. International Defense Review. March 1, 2002. Date Posted: February 14, 2002. http://kentaurus.com/downloads/IDRSub.pdf. Accessed 9 Feb 2019

Houghton RJ, Baber C, McMaster R, Stanton NA, Salmon P, Stewart R, Walker G (2006) Command and control in emergency 
services operations: a social network analysis. Ergonomics 49(12-13):1204-1225

Huddlestone J, Harris D (2017) Doing more with fewer people: Human Factors contributions on the road to efficiency and productivity. Cognit Technol Work 19(2-3):207-209

Ireland PN, Schuh S (2008) Productivity and US macroeconomic performance: interpreting the past and predicting the future with a twosector real business cycle model. Rev Econ Dyn 11(3):473-492

Klein G, Ross KG, Moon BM, Klein DE, Hoffman RR, Hollnagel E (2003) Macrocognition. IEEE Intell Syst 18(3):81-85

Klein G, Moon B, Hoffman RR (2006) Making sense of sensemaking 1: alternative perspectives. IEEE Intell Syst 4:70-73

Lim YT (2012) The study of a suitable for TMA filter architecture for the submarine with multiple sensors. J Korea Inst Mil Sci Technol 15(4):404-409

Loft S, Bowden V, Braithwaite J, Morrell DB, Huf S, Durso FT (2015a) Situation awareness measures for simulated submarine track management. Hum Factors 57(2):298-310

Loft S, Sadler A, Braithwaite J, Huf S (2015b) The chronic detrimental impact of interruptions in a simulated submarine track management task. Hum Factors 57(8):1417-1426

Lützhöft MH, Dekker SW (2002) On your watch: automation on the bridge. J Navig 55(1):83-96

Mankins JC (2009) Technology readiness assessments: a retrospective. Acta Astronaut 65(9-10):1216-1223

Negahdaripour S, Firoozfam P (2006) An ROV stereovision system for ship-hull inspection. IEEE J Ocean Eng 31(3):551-564

Pratt SJ (1988) U.S. Patent No. 4,771,721. U.S. Patent and Trademark Office, Washington, DC

Roberts AP, Cole JC (2018) Naturalistic decision making: taking a (cognitive) step back to take two steps forward in understanding experience-based decisions. J Appl Res Mem Cognit 7:70-81

Roberts AP, Stanton NA (2018) Macrocognition in submarine command and control: a comparison of three simulated operational scenarios. J Appl Res Mem Cognit 7:92-105

Roberts A, Stanton NA, Fay D (2015) The command team experimental test-bed stage 1: design and build of a submarine command room simulator. Procedia Manuf 3:2800-2807

Roco MC, Bainbridge WS (2003) Overview converging technologies for improving human performance. In: Roco MC, Bainbridge WS (eds) Converging technologies for improving human performance. Springer, Amsterdam, pp 1-27

Rudisill M (2000) Crew/automation interaction in space transportation systems: lessons learned from the glass cockpit. https://ntrs.nasa. gov/archive/nasa/casi.ntrs.nasa.gov/20040086769.pdf. Accessed 9 Feb 2019

Salas E, Burke CS, Samman SN (2001) Understanding command and control teams operating in complex environments. Inf Knowl Syst Manag 2(4):311-323

Salmon PM, Lenné MG, Walker GH, Stanton NA, Filtness A (2014) Exploring schema-driven differences in situation awareness between road users: an on-road study of driver, cyclist and motorcyclist situation awareness. Ergonomics 57(2):191-209

Salotti JM, Heidmann R, Suhir E (2014) Crew size impact on the design, risks and cost of a human mission to mars. In: Aerospace conference, 2014 IEEE, pp 1-9

Santos IJAL, Teixeira DV, Ferraz FT, Carvalho PVR (2008) The use of a simulator to include human factors issues in the interface design of a nuclear power plant control room. J Loss Prev Process Ind 21(3):227-238

Schutte PC (2017) How to make the most of your human: design considerations for human-machine interactions. Cognit Technol Work 19(2-3):233-249
Shar P, Li XR (2000) Passive sonar fusion for submarine C2 systems. IEEE Aerosp Electron Syst Mag 15(3):29-34

Showalter SE (2005) The law governing autonomous undersea vehicles: what an operator needs to know. In: OCEANS, 2005. Proceedings of MTS/IEEE, USA, pp 52-54

Simms A, Nichols T (2014) Social loafing: a review of the literature. J Manag Policy Pract 15(1):58

Stanton NA (2011) Trust in military teams. Ashgate, Aldershot

Stanton NA (2014) Representing distributed cognition in complex systems: how a submarine returns to periscope depth. Ergonomics 57(3):403-418

Stanton NA, Harvey C (2017) Beyond human error taxonomies in assessment of risk in sociotechnical systems: a new paradigm with the EAST 'broken-links' approach. Ergonomics 60(2):221-233

Stanton NA, Roberts APJ (2017) Examining social, information, and task networks in submarine command and control. IEEE Trans Hum Mach Syst 48:252-265

Stanton NA, Ashleigh MJ, Roberts AD, Xu F (2003) Virtuality in human supervisory control: assessing the effects of psychological and social remoteness. Ergonomics 46(12):1215-1232

Stanton NA, Baber C, Harris D (2008) Modelling command and control: event analysis of systemic teamwork. Aldershot, Ashgate

Stanton NA, Salmon P, Walker GH, Jenkins D (2010) Human factors in the design and evaluation of central control room operations. CRC Press, Boca Raton

Stanton NA, Rothrock L, Harvey C, Sorensen L (2015a) Investigating information-processing performance of different command team structures in the NATO Problem Space. Ergonomics 58(12):2078-2100

Stanton NA, Rothrock L, Harvey C, Sorensen L (2015b) Investigating performance of command team structures in the NATO problemapproach space. IEEE Trans Human-Machine Syst 45(6):702-713

Stanton NA, Harris D, Starr A (2016) The future flight deck: modelling dual, single and distributed crewing options. Appl Ergon 53:331-342

Stanton NA, Roberts APJ, Fay DT (2017) Up periscope: understanding submarine command and control teamwork during a simulated return to periscope depth. Cognit Technol Work 19(2-3):399-417

Stewart R, Stanton NA, Harris D, Baber C, Salmon P, Mock M, Kay A (2008) Distributed situation awareness in an airborne warning and control system: application of novel ergonomics methodology. Cognit Technol Work 10(3):221-229

Suleiman J, Watson RT (2008) Social loafing in technology-supported teams. Comput Support Coop Work 17(4):291-309

Walker GH, Stanton NA, Salmon PM, Jenkins DP (2008) A review of sociotechnical systems theory: a classic concept for new command and control paradigms. Theor Issues Ergonomics Sci 9(6):479-499

Walker GH, Stanton NA, Salmon PM, Jenkins DP (2009) Command and control: the sociotechnical perspective. Ashgate, Aldershot

Walker GH, Stanton NA, Baber C, Wells L, Gibson H, Salmon P, Jenkins D (2010a) From ethnography to the EAST method: a tractable approach for representing distributed cognition in. Air Traffic Control Ergon 53(2):184-197

Walker GH, Stanton NA, Salmon PM, Jenkins DP, Rafferty L, Ladva D (2010b) Same or different? Generalising from novices to experts in military command and control studies. Int J Ind Ergon 40(5):473-483

Walters B, French J, Barnes MJ (2000) Modeling the effects of crew size and crew fatigue on the control of tactical unmanned aerial vehicles (TUAVs). In: Simulation conference, 2000 Proceedings. Winter, vol 1, pp 920-924

Wang Z, Chen G, Blasch E, Lynch R, Pham K (2011) Submarine tracking via fusing multiple measurements based on Gaussian sum 
mixture approximation. In: Aerospace conference, March, 2011, IEEE. Curran Associates, New York, pp 1-7

Watkins M, Mukherjee A, Onder N, Mattila K (2009) Using agentbased modeling to study construction labor productivity as an emergent property of individual and crew interactions. J Constr Eng Manag 135(7):657-667
Zhang J, Patel VL (2006) Distributed cognition, representation, and affordance. Pragmat Cogn 14(2):333-341

Publisher's Note Springer Nature remains neutral with regard to jurisdictional claims in published maps and institutional affiliations. 